\title{
Comparison of WRF Model Physics Parameterizations over the MENA-CORDEX Domain
}

\author{
George Zittis ${ }^{1}$, Panos Hadjinicolaou ${ }^{1}$, Jos Lelieveld ${ }^{1,2}$ \\ ${ }^{1}$ Energy Environment and Water Research Center, The Cyprus Institute, Nicosia, Cyprus \\ ${ }^{2}$ Department of Atmospheric Chemistry, Max Plank Institute for Chemistry, Mainz, Germany \\ Email: g.zittis@cyi.ac.cy
}

Received 2 October 2014; revised 1 November 2014; accepted 28 November 2014

Copyright @ 2014 by authors and Scientific Research Publishing Inc.

This work is licensed under the Creative Commons Attribution International License (CC BY). http://creativecommons.org/licenses/by/4.0/

c) (i) Open Access

\section{Abstract}

We investigated the performance of 12 different physics configurations of the climate version of the Weather, Research and Forecasting (WRF) Model over the Middle East and North Africa (MENA) domain. Possible combinations among two Planetary Boundary Layer (PBL), three Cumulus (CUM) and two Microphysics (MIC) schemes were tested. The 2-year simulations (December 1988-November 1990) have been compared with gridded observational data and station measurements for several variables, including total precipitation and maximum and minimum 2-meter air temperature. An objective ranking method of the 12 different simulations and the selection procedure of the best performing configuration for the MENA domain are based on several statistical metrics and carried out for relevant sub-domains and individual stations. The setup for cloud microphysics is found to have the strongest impact on temperature biases while precipitation is most sensitive to the cumulus parameterization scheme and mainly in the tropics.

\section{Keywords}

WRF, Physics Parameterizations, Regional Climate Modeling, Sensitivity, MENA, CORDEX

\section{Introduction}

According to global climate projections [1], the already environmentally stressed Middle East and North Africa (MENA) region will be one of the most prominent climate change hotspots. Substantial decreases in precipitation, especially during the winter season and intense warming, most pronounced during summer, will probably have strong economic and societal impacts in the region [2]. The extreme conditions projected under scenarios 
of increasing greenhouse gas emissions will likely reduce availability of fresh water with repercussions for agriculture [2] [3], and increase energy demand in the region [2]. Moreover, since parts of the MENA are identified as biodiversity hotspots [4], implications for ecosystems should also be considered [5]. The timely design and implementation of mitigation measures and adaptation strategies is essential. However, the current resolution of global climate models (GCMs), of the order of $100-200 \mathrm{~km}$, is not sufficient for regional or national level impact studies, especially considering the steep climatic gradients and pronounced topography, and higher spatial resolution is required.

One of the well-established techniques to obtain high-resolution information adequate for impact studies is dynamical downscaling through regional climate modeling [6] [7]. Relatively coarse data derived from global models are used as initial and boundary conditions to drive the higher resolution limited-area models. Thus far projections from regional climate modeling efforts, which dynamically downscale the GCM fields (at resolutions of $50 \mathrm{~km}$ or higher) for the MENA region are limited in number (see Lelieveld et al. [2] and references therein). The World Climate Research Program (WRCP) through the Coordinated Regional Climate Downscaling Experiment-CORDEX ${ }^{1}$ and the establishment of the MENA-CORDEX domain aims to fill this gap. CORDEX provides guidelines for model experiments and coordination between research groups focusing on the region. Although part of the MENA is included in the CORDEX domains of Africa, Europe, Mediterranean and Central Asia, in most cases the region is located toward the boundaries of the aforementioned domains or is not adequately represented. The indications of an already changing climate, the increasing population in the region, the large potential for energy production from renewable sources (dependent on meteorological conditions) are some of the factors that highlight the need for improved climate projections over MENA. One such tool of dynamical climate downscaling is the Weather Research and Forecasting (WRF) model [8]. WRF is a next-generation meso-scale numerical weather prediction system, which is originally designed to serve operational forecasting needs and also atmospheric research. Nevertheless, over the last years its use as a regional climate model has been commonplace [9]-[14]. Regional climate modeling with WRF is not widespread in the MENA region, and most of the relevant studies focus either on Europe or Africa.

Parameterization of subgrid-scale phenomena remains to be one of the most challenging problems in numerical modeling of the atmosphere and climate [15] [16]. In the WRF system users have the flexibility to select from a wide range of different physics parameterizations (e.g. land surface, boundary layer, convection, cloud microphysics, radiation schemes). However, this choice can depend on the location of interest, type of application, horizontal and time resolutions or the type of the prevailing weather phenomena. Furthermore, different climate variables are found to be sensitive to different physical parameterizations [17], making the need for comprehensive sensitivity analyses more pressing and the procedure of physics parameterization selection more demanding. This type of uncertainties has received much attention over the last years. In particular, numerous studies discuss the WRF sensitivity to various parameterized physical processes for different simulation timescales (from 48 hours to a few months) and for different locations worldwide [15] [17]-[21]. From these studies it is deduced that the performance of the physics schemes varies according to the study region and the time of the year and therefore careful application for a specific domain is required. Also, when a long-term and highresolution climate experiment is designed some guidelines of the parameterization schemes that should be used (or avoided) would help to reduce computational requirements, data storage and increase time for analysis. In this context, we apply WRF over the MENA-CORDEX domain, and test the performance with 2-year simulations, combining parameterization schemes of three critical physical processes (convection, cloud microphysics and boundary layer representation) in order to provide a reference for potential users of WRF in the MENA region.

\section{Model and Data}

The CLWRF [22] set of modifications, implemented in the version 3.5.1 of WRF model, was used for the simulations of this study. The CLWRF feature used in this study is that the calculation of extreme values (i.e. maximum and minimum temperature) is computed over the time step and not the output values and is recorded. The extent of the CORDEX-MENA domain is presented in Figure 1, while the length of each simulation is 2 years (December 1988-November 1990), in addition to one month of spin-up time (November 1988), which was excluded from our analysis. We have used a horizontal resolution of $0.44^{\circ}(\approx 50 \mathrm{~km})$ and 30 vertical levels. The ERA-Interim reanalysis dataset [23] was used to provide initial and boundary conditions. The latter were up-

${ }^{1}$ http://wcrp-cordex.ipsl.jussieu.fr/ 


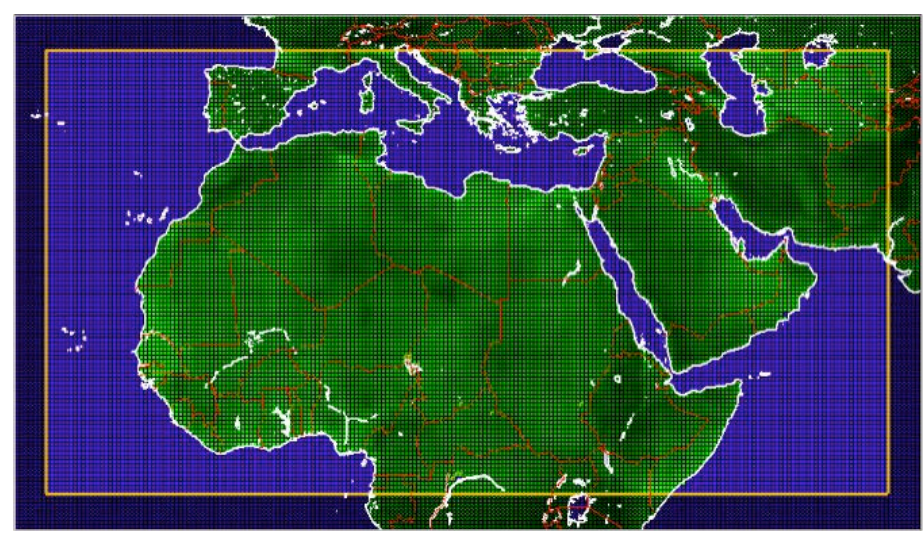

Figure 1. Orography representation of the CORDEX-MENA domain in a 50-km resolution grid.

dated every six hours.

The interactions between physical process parameterizations in WRF are presented in Figure 2. Our study includes all 12 possible combinations of the following parameterizations (see also Table 1).

1) Planetary Boundary Layer (PBL)

-Yonsei University (YSU) scheme [24]. A non-local scheme with explicit treatment of entrainment processes at the top of the PBL, suitable for weather forecasting and climate prediction models.

-Mellor-Jamada-Janjic (MYJ) scheme [25]. A local scheme with TKE-based vertical mixing in boundary layer and free atmosphere.

2) Cumulus Physics (CUM)

-Kain-Fritsch (KF) scheme [26] [27]. A shallow sub-grid scheme that uses a mass flux approach with downdrafts and CAPE removal timescale closure. It includes condensed and gaseous water detrainment. The clouds persist over the convective time scale.

-Betts-Miller-Janjic (BMJ) scheme [25] [28] [29]. An adjustment type scheme. It generates deep and shallow convection. Relaxing is applied towards variable temperature and humidity profiles determined from thermodynamic considerations.

-Grell-Devenyi (GD) ensemble scheme. Multi-closure, multi-parameter ensemble method that explicitly accounts for updrafts and downdrafts.

3) Cloud Microphysics (MIC)

-WRF Single-Moment 6-class (WSM6) scheme [30]. A 6-class scheme that includes ice, snow and graupel formation processes.

-Goddard (GCE) scheme [31]. A saturation adjustment 6-class microphysics scheme with graupel and timesplit fall terms with melting.

4) Radiation (RAD)

-CAM short and long wave radiation schemes [32]. Both CAM are spectral schemes that interact with clouds, trace gases and aerosols. CLWRF modifications use these schemes to provide a flexible way to alter the greenhouses gas forcing in the model [22]. Since we are planning to use these modifications for future climate projections, CAM radiation schemes were used in all simulations.

5) Land Surface Model (LSM)

-Noah LSM [33]. A scheme with soil moisture and temperature in four subsurface layers. It also includes the effects of vegetation, fractional snow cover and frozen soil physics. It was used in all simulations. learly, this selection does not encompass the whole list of available WRF physics parameterizations due to their large number that can generate hundreds of combinations. However, the selected schemes are found to be commonly used in climate studies in the relevant literature or suggested in the model users guide [34]. For example, Mooney et al. [35] suggest that CAM is the most suitable shortwave scheme for climate simulations as its ozone distribution varies during the simulation according to monthly zonal-mean climatology data. Similarly, Bukovsky and Karoly [18] indicate that the CAM long and short wave radiation scheme is more appropriate for simulations of 30 - $90 \mathrm{~km}$ resolution. They also tested the KF and BMJ cumulus schemes and found that the former performs 


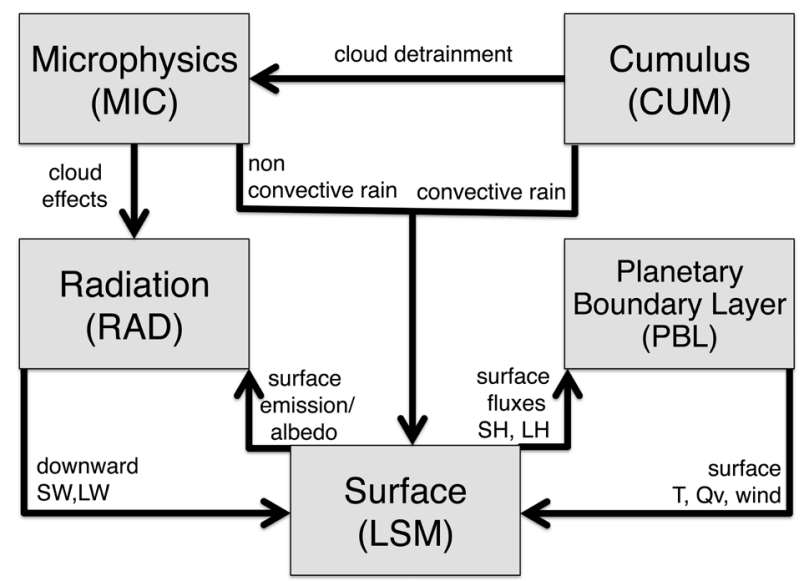

Figure 2. Interactions of physical parameterizations in WRF model (redrawn from Dudhia 2014).

Table 1. Parameterization schemes for physical processes for each of the 12 CLWRF simulations.

\begin{tabular}{ccccccccccccc}
\hline Sim. ID & $\mathbf{1}$ & $\mathbf{2}$ & $\mathbf{3}$ & $\mathbf{4}$ & $\mathbf{5}$ & $\mathbf{6}$ & $\mathbf{7}$ & $\mathbf{8}$ & $\mathbf{9}$ & $\mathbf{1 0}$ & $\mathbf{1 1}$ & $\mathbf{1 2}$ \\
\hline PBL & YSU & YSU & YSU & MYJ & MYJ & MYJ & YSU & YSU & YSU & MYJ & MYJ & MYJ \\
CUM & KF & GD & BMJ & KF & GD & BMJ & KF & GD & BMJ & KF & GD & BMJ \\
MIC & WSM6 & WSM6 & WSM6 & WSM6 & WSM6 & WSM6 & GCE & GCE & GCE & GCE & GCE & GCE \\
LSM & NOAH & NOAH & NOAH & NOAH & NOAH & NOAH & NOAH & NOAH & NOAH & NOAH & NOAH & NOAH \\
RAD & CAM & CAM & CAM & CAM & CAM & CAM & CAM & CAM & CAM & CAM & CAM & CAM \\
\hline
\end{tabular}

better in terms of precipitation over a domain covering North America. Mercader et al. [36], testing the KF, BMJ and GD convection schemes, identified KF as the most skillful for temperature forecasting. Ruiz et al. [19] have tested the same PBL and convection schemes as in our study but for South America. They found that temperature, humidity and depth of the boundary layer are best represented by the YSU scheme. Flaounas et al. [20], studying a region similar to the MENA-CORDEX domain, found that the KF cumulus in combination with the MYJ PBL scheme is representing better the onset of the West African Monsoon, a climate feature also relevant for this study. Among other physics parameterizations, Evans et al. [17] have tested the YSU and MYJ PBL schemes in combination with the KF and BMJ convection schemes in their multi-physics climate study over Southeast Australia. Argüeso et al. [37] and Soares et al. [12], downscaling the ERA-40 for Southern Spain and ERA-Interim for Portugal, support the use of the WSM microphysics, MYJ planetary boundary layer and MBJ convections schemes.

Surface meteorological variables extracted from the model output were compared with the similar resolution $\left(0.5^{\circ}\right)$ CRU gridded monthly observational dataset, version TS3.10 [38]. The comparison focused on maximum (TX), minimum (TN) temperature and precipitation (PR). Moreover, CRU cloud cover (CLD), expressed in fraction, was complementarily used in order to attribute some of the surface variables biases. To consider observational spread [39] [40] in the analysis, two complementary gridded datasets of precipitation were also utilized in the analysis. These are the GPCC [41] and University of Delaware ${ }^{2}$ monthly precipitation datasets. Unfortunately, besides CRU, no additional TX and TN gridded data were available in the desired time resolution. Moreover, daily observations derived from the ECA \& D dataset [42] were used for 12 selected locations of MENA (Figure 3-right panel). The choice of stations was based on the availability of time consistent datasets for the 2-year period of interest and the spread of stations across the region. This selection covers a range of different climate regimes and elevations. More details about the selected stations and the data availability over the 2-yr period of simulations are presented in Table 2.

${ }^{2}$ The University of Delaware precipitation data are provided by the NOAA/OAR/ESRL PSD, Boulder, Colorado, USA, from their Web site at http://www.esrl.noaa.gov/psd// 

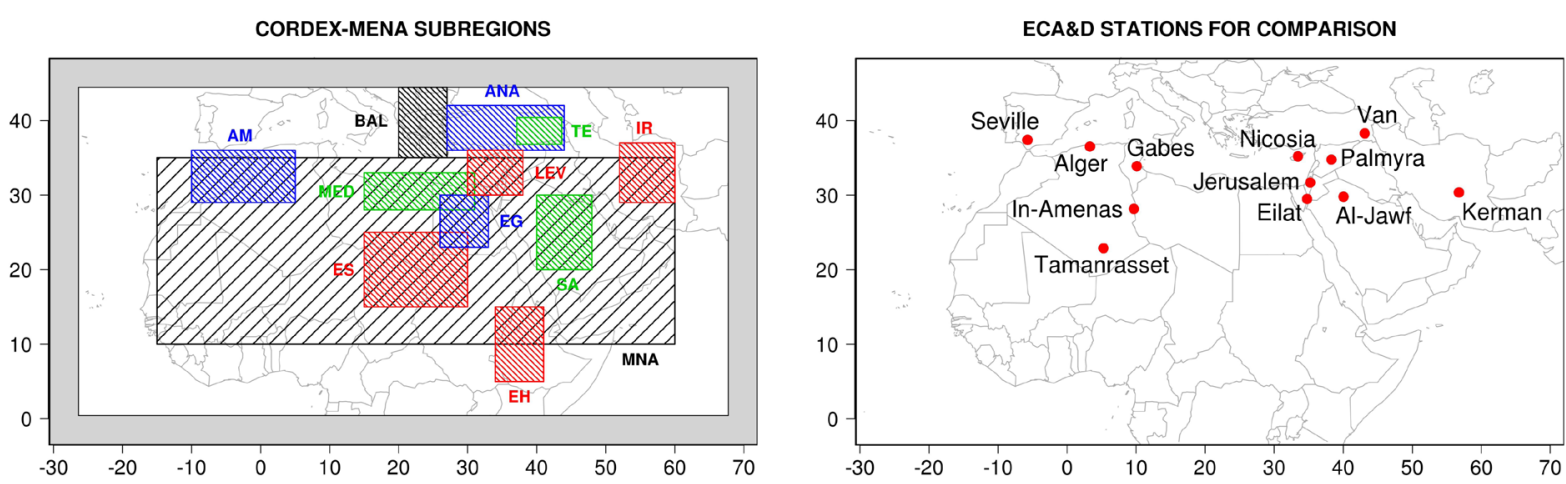

Figure 3. Definition of the 12 sub-regions within the CORDEX-MENA domain (left panel) and location of the selected ECA \& D stations for comparison (right panel).

Table 2. ECA \& D stations details (station name, country, availability on maximum (TX), minimum (TN) temperature and precipitation (PR), real and modeled station elevations).

\begin{tabular}{|c|c|c|c|c|c|c|c|c|c|c|c|c|c|}
\hline Station & Country & $\mathbf{T x}$ & Tn & Pr & $\begin{array}{c}\text { Model } \\
\text { Elev. } \\
\text { (Meters) }\end{array}$ & $\begin{array}{c}\text { Real } \\
\text { Elev. } \\
\text { (Meters) }\end{array}$ & Station & Country & $\mathbf{T x}$ & Tn & Pr & $\begin{array}{l}\text { Model } \\
\text { Elev. } \\
\text { (Meters) }\end{array}$ & $\begin{array}{c}\text { Real } \\
\text { Elev. } \\
\text { (Meters) }\end{array}$ \\
\hline 1. Alger & Algeria & Q & Q & Q & 402 & 24 & 7. Seville & Spain & Q & Q & $\square$ & 142 & 34 \\
\hline 2. Al-Jouf & S. Arabia & Q & Q & & 688 & 689 & 8. Van & Turkey & प & $\square$ & $\square$ & 2204 & 1662 \\
\hline 3. Gabes & Tunisia & ૫ & Q & Q & 58 & 4 & 9. In-Amenas & Algeria & Q & $\square$ & & 610 & 561 \\
\hline 4. Jerusalem & Israel & प & $\square$ & $\square$ & 387 & 815 & 10. Palmyra & Syria & $\square$ & $\square$ & $\square$ & 693 & 404 \\
\hline 5. Kerman & Iran & $\square$ & $\square$ & $\square$ & 2123 & 1754 & 11. Tamanrasset & Algeria & $\square$ & $\square$ & & 1324 & 1362 \\
\hline 6. Nicosia & Cyprus & Q & प & $\square$ & 132 & 160 & 12. Eilat & Israel & $\square$ & ૫ & $\square$ & 620 & 12 \\
\hline
\end{tabular}

\section{Methods and Metrics}

\subsection{Sensitivity Analysis}

In order to isolate the effect of each physics scheme from the total configuration, we have calculated the mean differences between simulations that only differ in one type of physical parameterization (PBL, MIC or CUM), while the rest of the setup is identical. For example, to explore how different the results between the two PBL schemes can be, we created composites of the differences between runs with IDs 1 - 4, 2 - 5, 3 - 6, 7 - 10, 8 - 11, and 9 - 12 (see Table 1). Similar differences were calculated for the CUM and MIC parameterizations. Relevant sensitivity plots of these differences can indicate how sensitive each of the tested surface variables is to the parameterization of the selected physical processes in the WRF model and for the MENA region.

\subsection{Evaluation Metrics and Ranking}

As mentioned above, in this WRF physics inter-comparison we focus on three surface variables, being most relevant for impact studies. Analysis for monthly PR, TX and TN was performed. In order to objectively explore the performance of each simulation, we used a range of statistical metrics after calculating the monthly values of the model output and the gridded observational data. For precipitation observations we averaged the three available datasets on a monthly basis. A short description of each metric is presented in the following.

- The Pearson's correlation coefficient (COR), a measure of linear correlation between the observations (OBS) and simulations (SIM)

$$
C O R=\frac{\operatorname{COV}(\mathrm{OBS}, \mathrm{SIM})}{\sigma_{\text {OBS }} \times \sigma_{\text {SIM }}}=\frac{\sum_{i=1}^{n}\left(\mathrm{OBS}_{i}-\overline{\mathrm{OBS}}\right)\left(\mathrm{SIM}_{i}-\overline{\mathrm{SIM}}\right)}{\sigma_{\text {OBS }} \times \sigma_{\text {SIM }}}
$$

where $n$ is the number of the sample, $C O V$ is covariance and $\sigma$ is the standard deviation. 
- The Mean Absolute Error (MAE), used to describe the average model performance error. This metric has some advantages over the widely used Root Mean Square Error [43]. In this study, the authors suggest that RMSE tends to become increasingly larger than MAE (but not necessarily in a monotonic fashion) as the distribution of error magnitudes becomes more variable. This makes $M A E$ a more natural measure of average error magnitude.

$$
M A E=\frac{1}{n} \sum_{i=1}^{n}\left|S I M_{i}-O B S_{i}\right|
$$

- The Modified Index of Agreement (MIA), as a standardized measure of the degree of the model prediction error. This index varies between 0 and 1 . It was introduced by Willmott [44] and refined by Legates and McCabe [45]

$$
M I A=1-\frac{\sum_{i=1}^{n}\left(\mathrm{OBS}_{i}-\mathrm{SIM}_{i}\right)}{\sum_{i=1}^{n}\left|\operatorname{SIM}_{i}-\overline{\mathrm{OBS}}\right|+\left|O B S_{i}-\overline{\mathrm{OBS}}\right|}
$$

- The error in the standard deviation (STDE) of the two samples (monthly OBS and SIM) to explore if the modeled variability realistically represents the that of the observations.

$$
S T D E=\frac{1}{n} \sum_{i=1}^{n}\left|\sigma_{\mathrm{OBS}_{i}}-\sigma_{S I M_{i}}\right|
$$

The statistical metrics described in the previous paragraph were applied to the monthly time-series of the gridded observational data and each of the 12 CLWRF simulations. Every grid point of the MENA domain was independently analyzed. For each grid point the 12 runs were ranked according to their metrics performance for all of the three variables (TX, TN and PR). All variables and scores were equally weighted in the ranking. Finally, the total number of grid points where each run was ranked first was recorded. The runs with the highest number of first-ranking grid points are considered as the best performing ones.

Because of the large areal extent of the MENA-CORDEX domain, the selection might be biased from the performance over grid points not necessarily relevant for studies over the traditional MENA definition territories $^{3}$, especially near the tropics. To avoid this, we repeated the analysis including only grid points over subdomains of special interest, which are defined in Figure 3 (left panel). These sub-regions include the most densely populated areas and the sources of the most important rivers of the region. These are the core-MENA (MNA) region, the Atlas Mountains (AM), the northeast Mediterranean coast of Africa (MED), the east Sahara territories (ES), the Ethiopian Highlands (EH), Egypt (EG), Saudi Arabia (SA), Iran (IR), the Balkans (BAL), the Anatolian Peninsula (ANA), the sources of Tigris and Euphrates rivers region (TE) and the Levantine (LEV). Some of the above mentioned regions overlap. Since the CRU dataset does not cover water bodies, the analysis was restricted to land grid points. A similar type of analysis between the ECA\&D station data and the closest model grid points was performed.

\section{Results}

\subsection{Maximum Temperature Biases}

The average TX of the CRU data for the study period is presented in the left panel of Figure 4 as a reference while the mean annual TX biases between the 12 ensemble members and the CRU data are depicted in Figure 5. It is clear from the bias maps that the model performs better for the runs where the WSM6 microphysics scheme is used (IDs 1, 2, 3, 4, 5 and 6). On the contrary, the majority of the simulations using the GCE scheme (IDs 7, 8, 9, 10, 11 and 12) tend to strongly underestimate TX especially over the African part of the domain. These large TX departures from CRU observations reach up to $10^{\circ} \mathrm{C}$. This coincides with the increased cloudiness produced by the latter scheme over the locations of the strongest TX overestimation (c.f. Figure 5 and Figure 6). These positive cloud biases generated for the GCE-driven runs (Figure 6) limit the incoming solar radiation and thus induce large negative temperature biases.

The more realistically produced TX for the WSM6 microphysics scheme over the core-MENA subdomain is also clear in the time-series comparison of Figure 7 (left panel). In general, the seasonal cycle of TX is captured

${ }^{3}$ http://www.worldbank.org/en/region/mena 

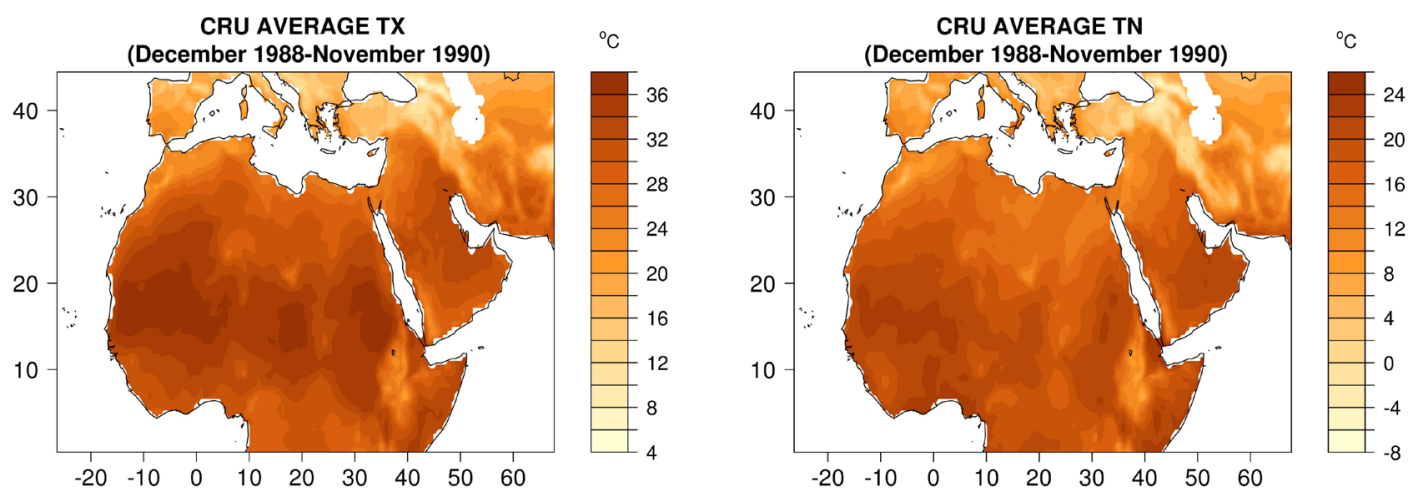

Figure 4. CRU maximum (TX-left panel) and minimum (TN-right panel) temperature, averaged over the period December 1988-November 1990.

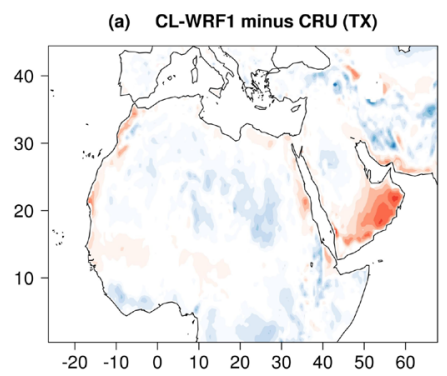

(d) CL-WRF4 minus CRU (TX)

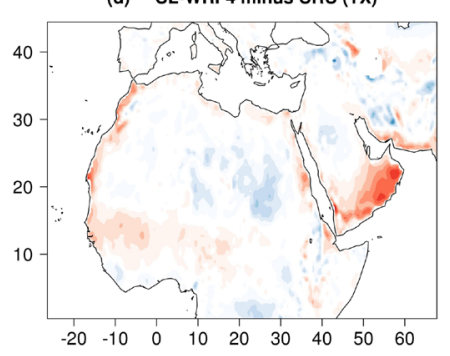

(g) CL-WRF7 minus CRU (TX)

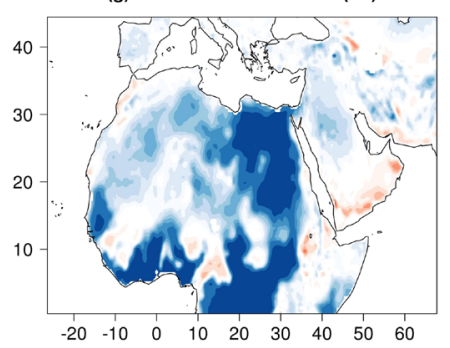

(j) CL-WRF10 minus CRU (TX)

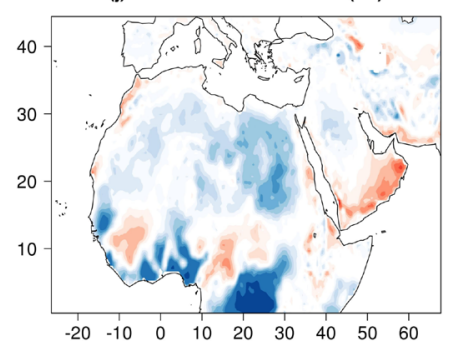

(b) CL-WRF2 minus CRU (TX)

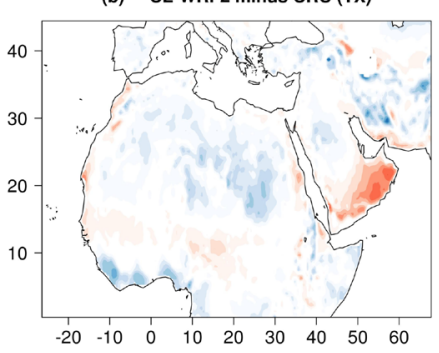

(e) CL-WRF5 minus CRU (TX)

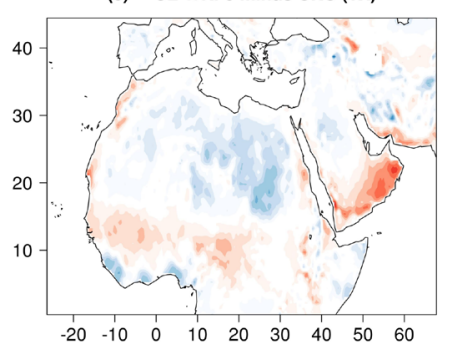

(h) CL-WRF8 minus CRU (TX)

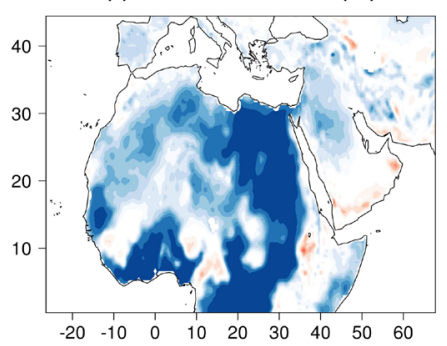

(k) CL-WRF11 minus CRU (TX)

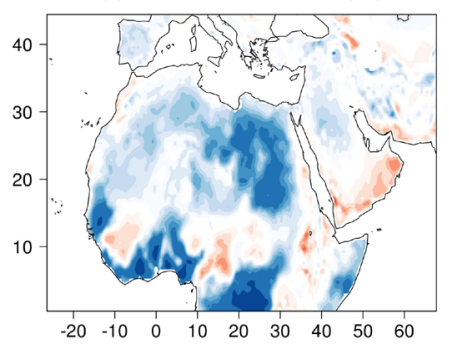

(c) CL-WRF3 minus CRU (TX)

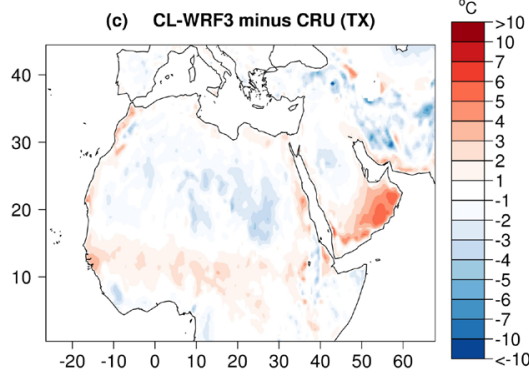

(f) CL-WRF6 minus CRU (TX)

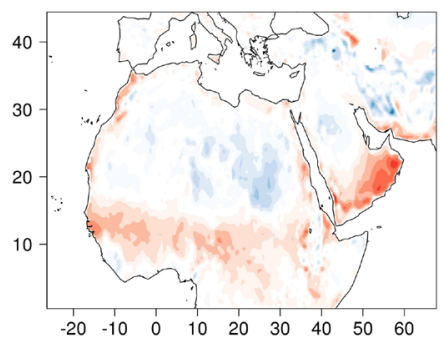

(i) CL-WRF9 minus CRU (TX)

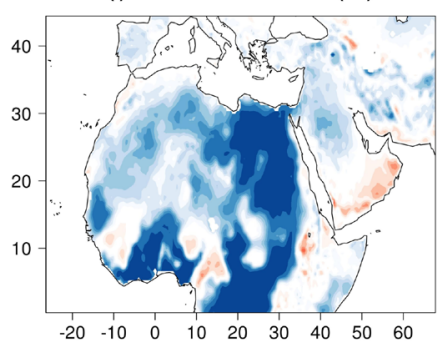

(I) CL-WRF12 minus CRU (TX)

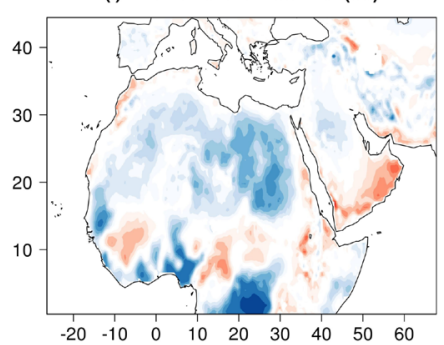

Figure 5. Annual maximum temperature (TX) absolute biases of the 12 CLWRF simulations relative to CRU data averaged over the period December 1988-November 1990. 


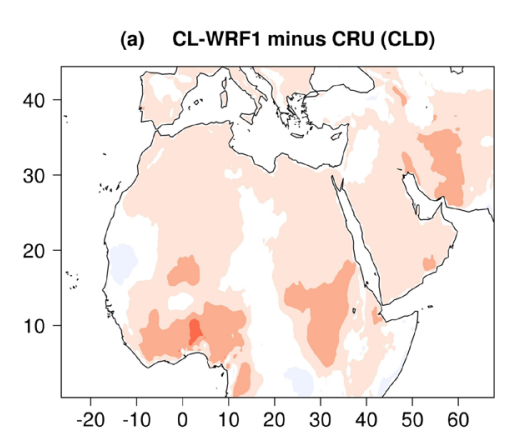

(d) CL-WRF4 minus CRU (CLD)

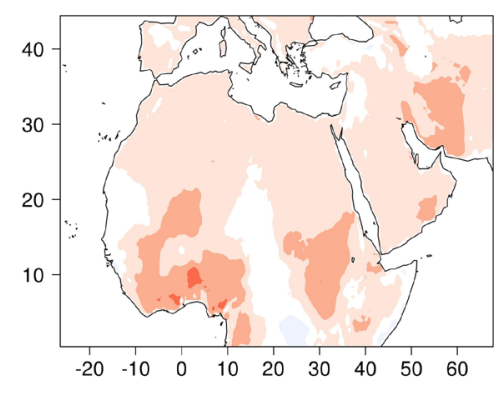

(g) CL-WRF7 minus CRU (CLD)
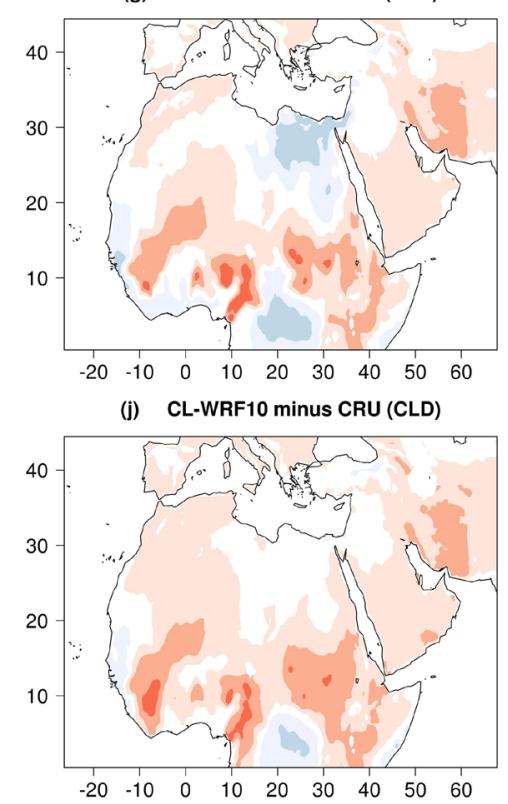

(b) CL-WRF2 minus CRU (CLD)

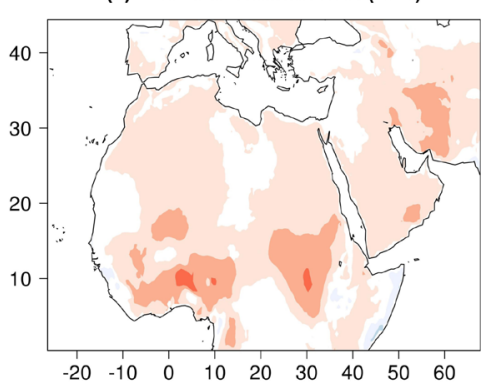

(e) CL-WRF5 minus CRU (CLD)

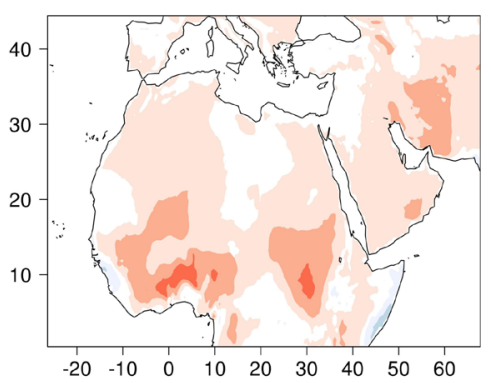

(h) CL-WRF8 minus CRU (CLD)

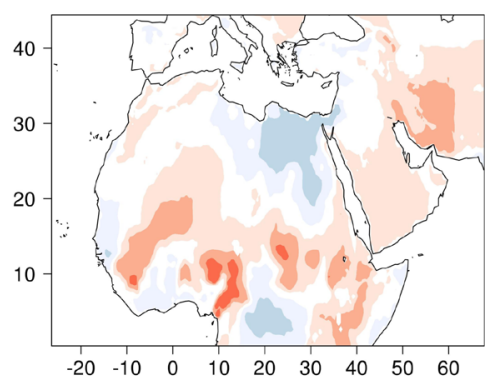

(k) CL-WRF11 minus CRU (CLD)

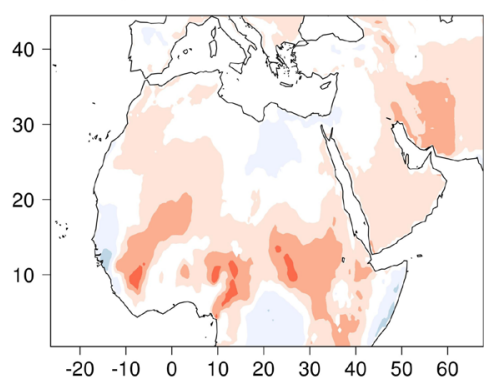

(c) CL-WRF3 minus CRU (CLD)

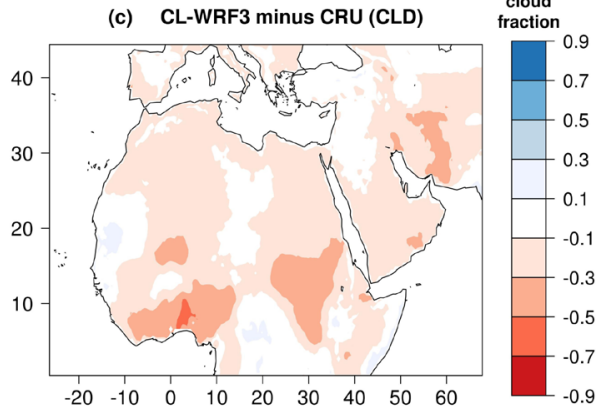

(f) CL-WRF6 minus CRU (CLD)

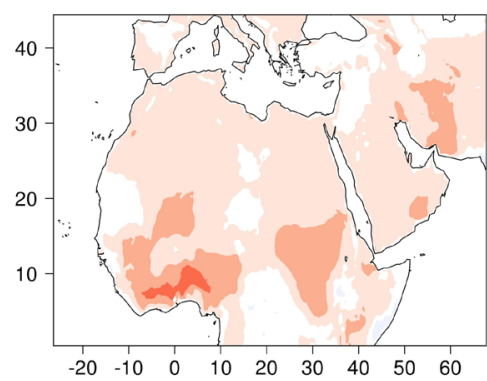

(i) CL-WRF9 minus CRU (CLD)

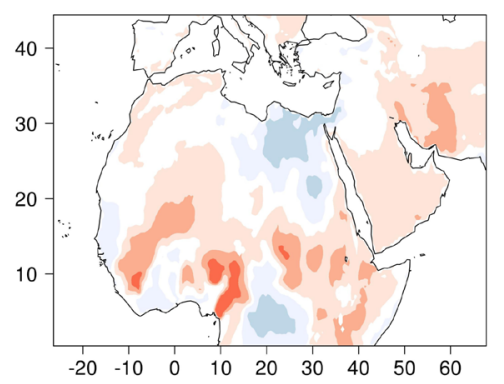

(l) CL-WRF12 minus CRU (CLD)

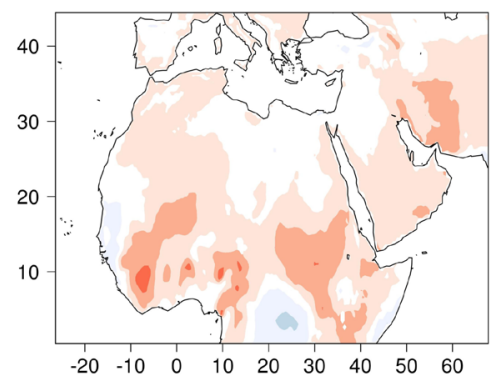

Figure 6. Mean annual cloud cover (CLD) absolute biases of the 12 CLWRF simulations relative to CRU data (December 1988-November 1990).

well by most of the simulations; however, the model performance is relatively better for the transition seasons between winter and summer (i.e., the monsoon).

A consistent overestimation of TX for all simulations over the southern Arabian Peninsula is also evident for the forcing ERA-Interim data in the same region and strong temperature biases are found when they are compared with CRU [46].

We find that the choice between the two selected PBL schemes is not critical for TX as the mean differences between all simulations are small (not shown). Similarly, the cumulus parameterization selection appears to be of minor influence on TX compared to the MIC selection. For most of the domain the differences between the three tested CUM schemes as derived from the sensitivity plots (not shown) are less than $1^{\circ} \mathrm{C}$. 

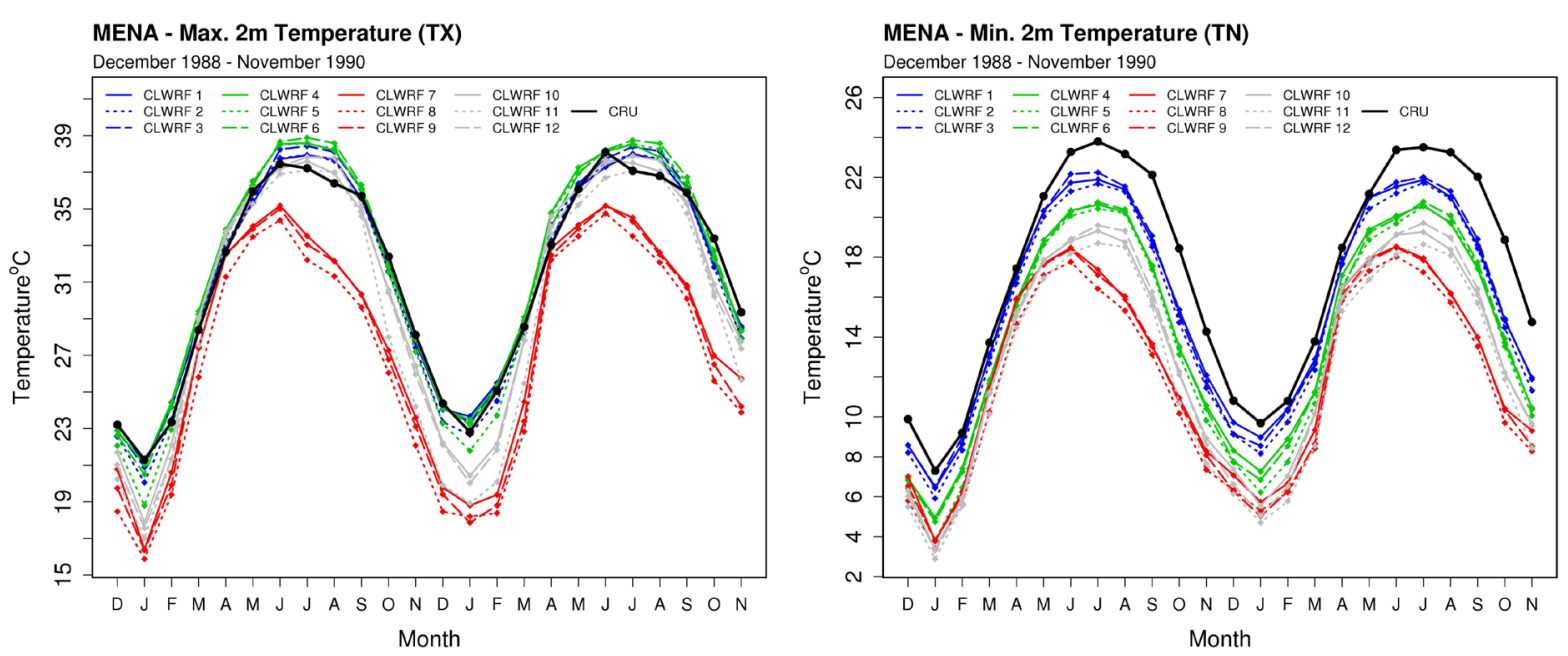

Figure 7. Monthly maximum (left) and minimum temperature (right) time-series of CRU data and 12 CLWRF simulations averaged for the core MENA subdomain defined in Figure 3.

\subsection{Minimum Temperature Biases}

The CRU reference of TN averaged for the December 1988-November 1990 period is presented in Figure 4 (right panel). TN biases (Figure 8) are in general larger and more extensive than TX biases. Consistent with the latter though, the model performs better for runs with the WSM6 microphysics scheme (IDs 1, 2, 3, 4, 5, and 6). The mean difference between the two schemes is also presented in Figure 9 (right panel). Large deviations, up to more than $8^{\circ} \mathrm{C}$ are found. In general, the WSM6 yields higher TN and is closer to observations (Figures 8(a)-(f)). TN differences related to the PBL parameterizations are smaller (Figure 9-left panel), however, the YSU scheme is, over most of the MENA, relatively warmer $\left(1^{\circ} \mathrm{C}-3^{\circ} \mathrm{C}\right)$ than the MYJ scheme. This feature is more prominent over the desert areas of the domain. Similarly with TX, TN appears to be relatively insensitive to the selection of CUM parameterization (not shown). The monthly TN time-series averaged for the coreMENA domain are presented in Figure 7 (right panel). Simulations with the WSM6 microphysics scheme (blue and green lines) consistently perform better over the study period and capture well the inter-annual variability of the observations within the 2-year study period. In agreement with the TX time-series, this is more evident during the transitional seasons and mainly during spring.

\subsection{Precipitation Biases}

Annual mean absolute PR biases are depicted in Figure 10. The annual observations for this figure (OBS) were produced by the averaging the three available gridded datasets (CRU, GPCC and University of Delaware) for the study period. Biases from each individual dataset were also checked but since the patterns were found to be very similar they are not presented. In all cases the dry North African and Middle East part of the domain is realistically simulated. However, since this region is ultra-arid, we explored in more depth the relationship between the simulations and OBS data by calculating the relative PR biases expressed in percentages (Figure 11). The reference OBS annual precipitation for the two years of simulations and for each of the three datasets is presented in Figure 12. There are obvious similarities in the precipitation patterns of the three datasets for these two years of comparison. Yet local differences exist. For example the Ethiopian Highlands are found to be relatively wetter in the GPCC dataset while the Sahara desert is found relatively drier in the University of Delaware observations. More information regarding the differences of the selected gridded precipitation datasets and over the northernmost part of the MENA-CORDEX domain can be found in Tanarhte et al. [40]. A consistent overestimation of precipitation (up to a factor of two relative to CRU) over the Sahara desert is evident in all simulations. Nevertheless, these high percentages should be viewed from the perspective that the observed amounts of precipitation are very low $(0-10 \mathrm{~mm} /$ year). Noteworthy, absolute PR biases (of the order of $1000 \mathrm{~mm} /$ year or more) are found in large parts of the domain and especially in low latitudes. In the tropics, the WSM6 microphysics scheme (used in runs with IDs 1, 2, 3, 4, 5 and 6) is generally much wetter than GCE (runs with IDs 7, 8, 
(a) CL-WRF1 minus CRU (TN)

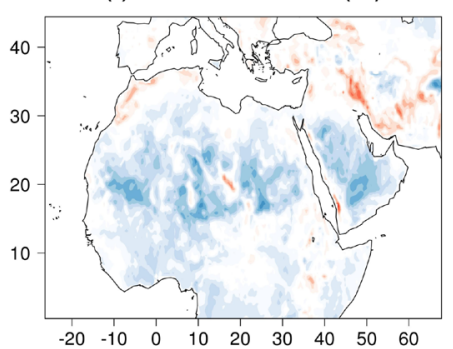

(d) CL-WRF4 minus CRU (TN)

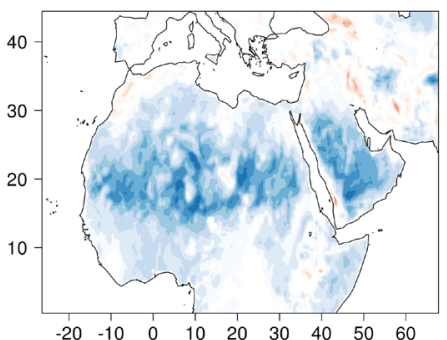

(g) CL-WRF7 minus CRU (TN)

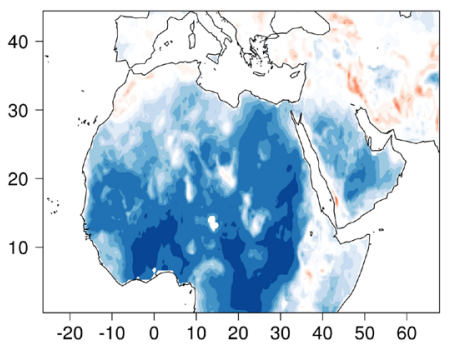

(j) CL-WRF10 minus CRU (TN)

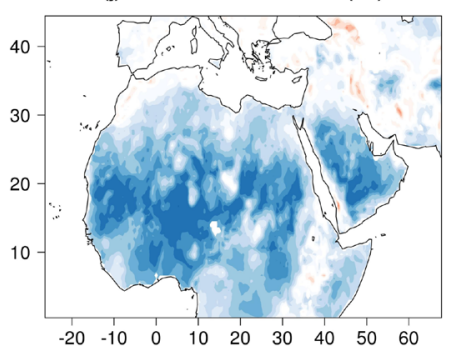

(b) CL-WRF2 minus CRU (TN)

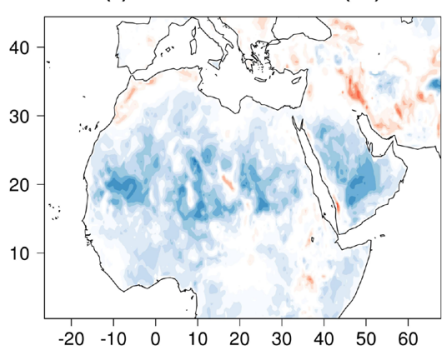

(e) CL-WRF5 minus CRU (TN)

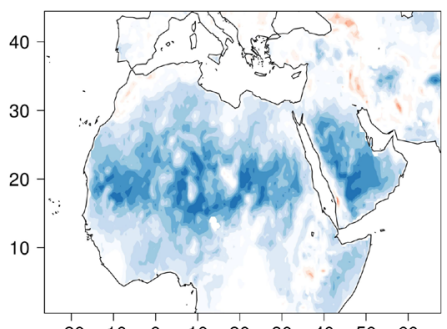

$\begin{array}{lllllllll}-20 & -10 & 0 & 10 & 20 & 30 & 40 & 50 & 60\end{array}$ (h) CL-WRF8 minus CRU (TN)

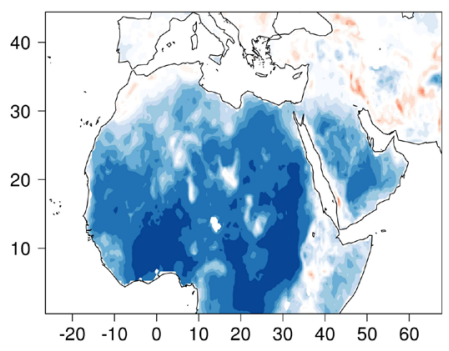

(k) CL-WRF11 minus CRU (TN)

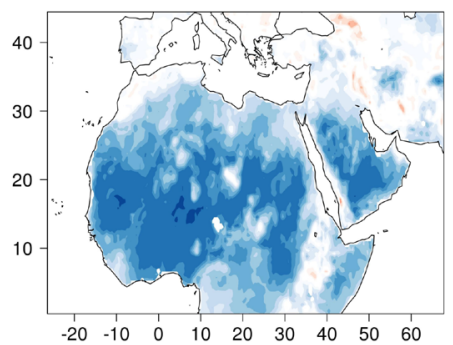

(c) CL-WRF3 minus CRU (TN)

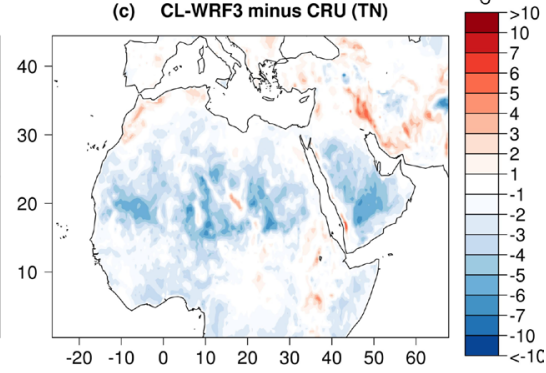

(f) CL-WRF6 minus CRU (TN)

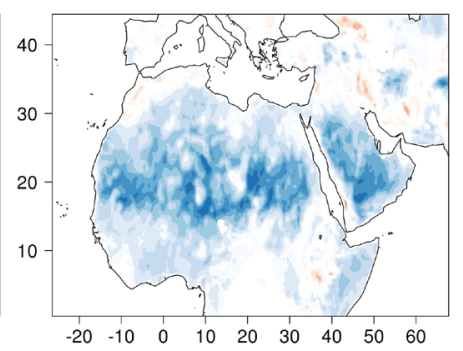

(i) CL-WRF9 minus CRU (TN)

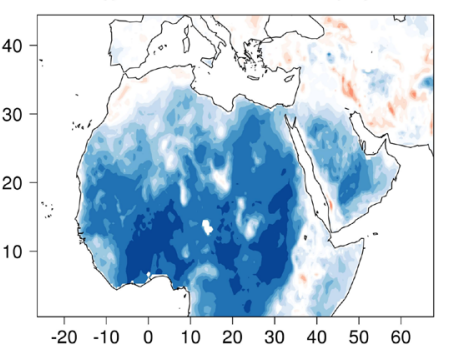

(I) CL-WRF12 minus CRU (TN)

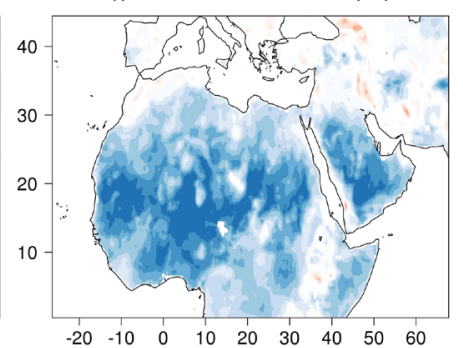

Figure 8. Annual minimum temperature (TN) absolute biases of the 12 CLWRF simulations relative to CRU data averaged over the period December 1988-November 1990.
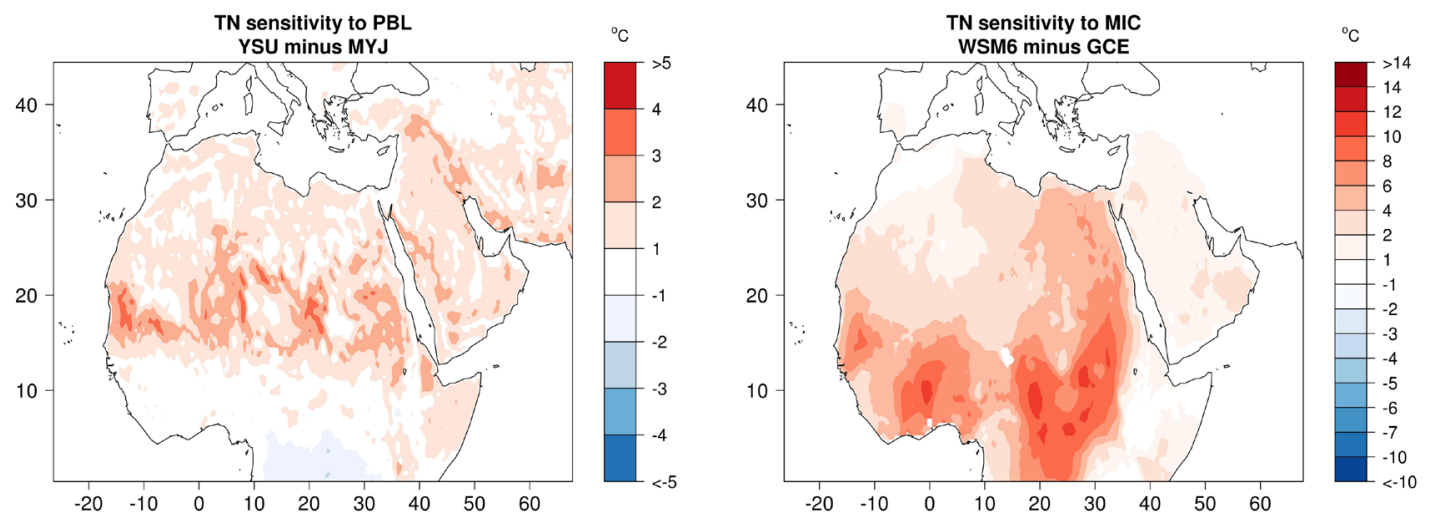

Figure 9. Minimum temperature (TN) sensitivity to PBL (left panel) and MIC (right panel) physics selection. 
(a) CL-WRF1 minus OBS. (PR)

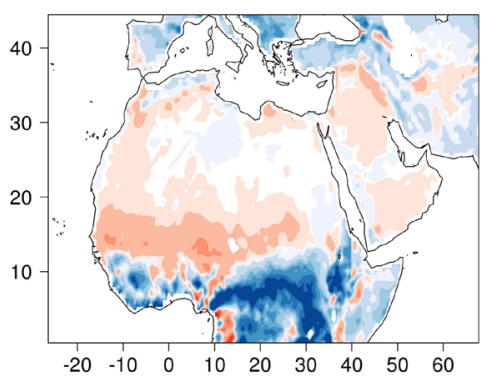

(d) CL-WRF4 minus OBS. (PR)

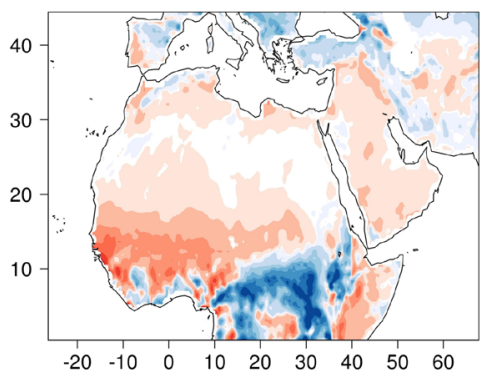

(g) CL-WRF7 minus OBS. (PR)

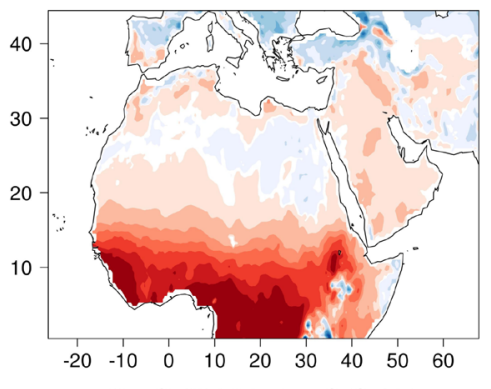

(j) CL-WRF10 minus OBS. (PR)

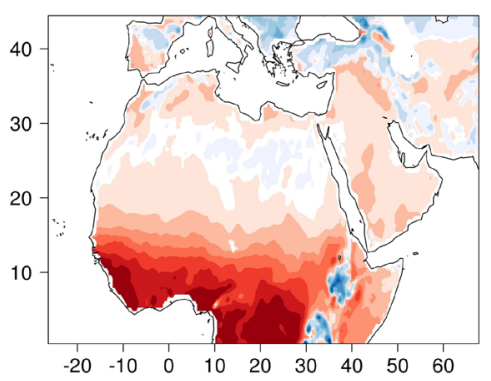

(b) CL-WRF2 minus OBS. (PR)

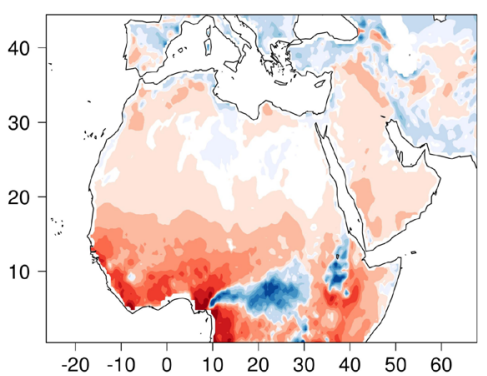

(e) CL-WRF5 minus OBS. (PR)

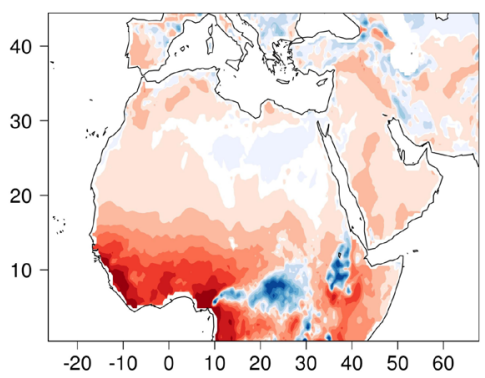

(h) CL-WRF8 minus OBS. (PR)

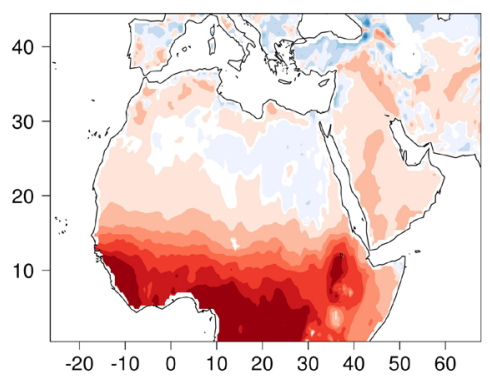

(k) CL-WRF11 minus OBS. (PR)

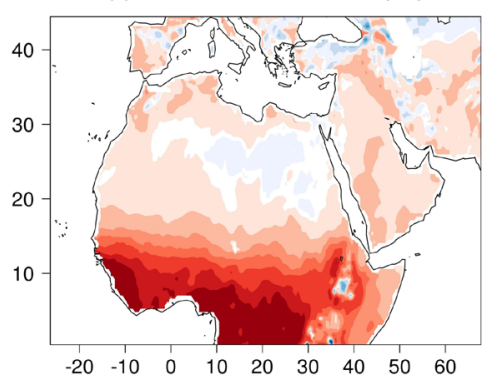

(c) CL-WRF3 minus OBS. (PR)

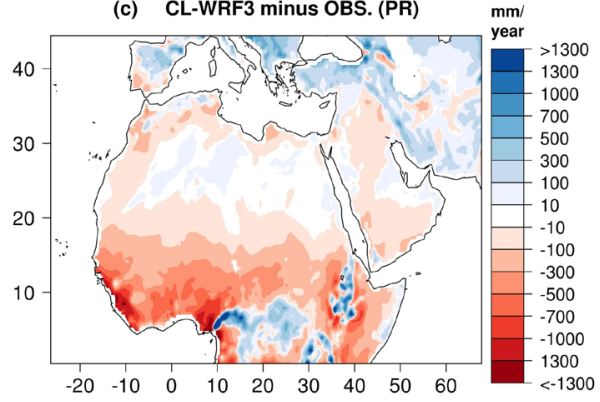

(f) CL-WRF6 minus OBS. (PR)

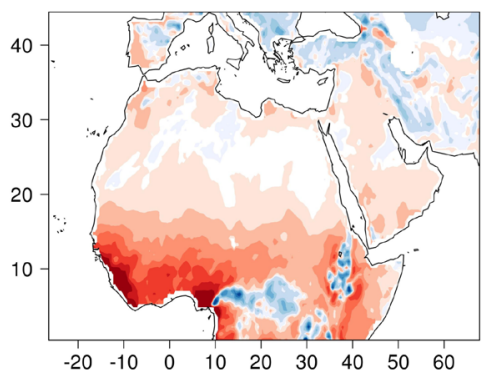

(i) CL-WRF9 minus OBS. (PR)

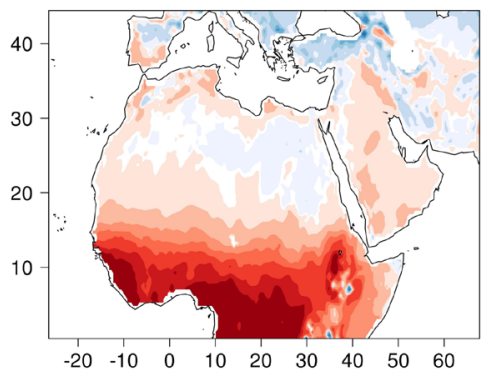

(I) CL-WRF12 minus OBS. (PR)

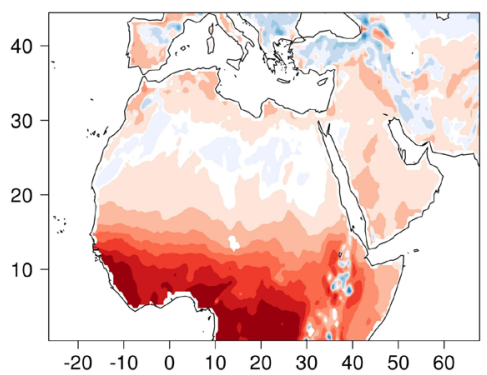

Figure 10. Mean annual precipitation (PR) absolute biases of the 12 CLWRF simulations relative to the average of the observational datasets (December 1988-November 1990).

9, 10, 11 and 12). This is shown in the relevant sensitivity map (Figure 13-top left panel). From the PR biases of Figure 10 it is not clear which of the two microphysics options is closer to the observations as runs under WSM6 are generally wetter and runs under GCE are drier than OBS. Nevertheless, the scores of the statistical metrics for the core-MENA sub domain (Table 3) are generally better for the former scheme. The PR monthly time-series of Figure 14 corroborate the closer agreement between WSM6-driven runs (green and blue lines) and CRU observations (black line). From this plot it is evident that for this sub-domain, simulations with IDs 1, $2,3,4,5$, and 6 capture reasonably well the seasonal cycle of precipitation and the timing of the wettest months of the period of study.

The PR sensitivity to the CUM parameterization is depicted in the top right and bottom panels of Figure 13. As expected, the southernmost part of the MENA domain, where deep convection is prevailing, shows the larg- 
(a) CL-WRF1 vs. OBS. (PR)

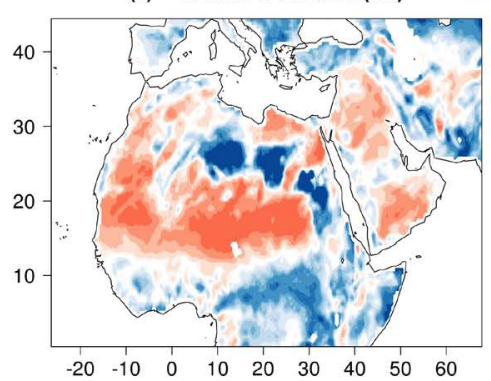

(d) CL-WRF4 vs. OBS. (PR)

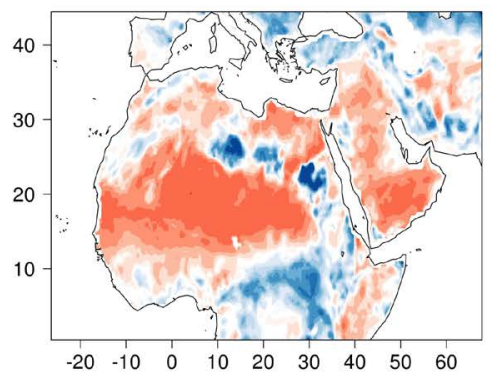

(g) CL-WRF7 vs. OBS. (PR)

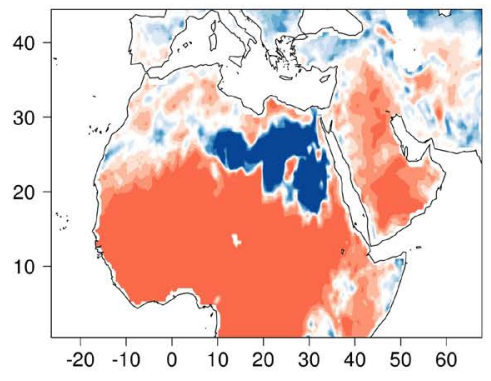

(j) CL-WRF10 vs. OBS. (PR)

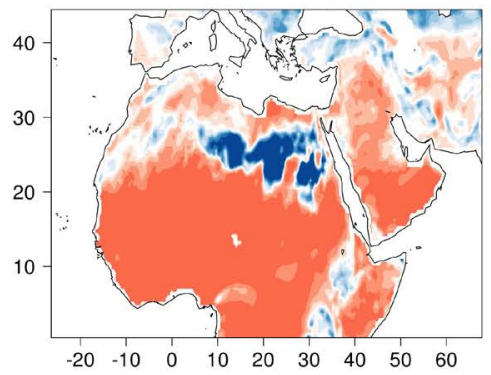

(b) CL-WRF2 vs. OBS. (PR)

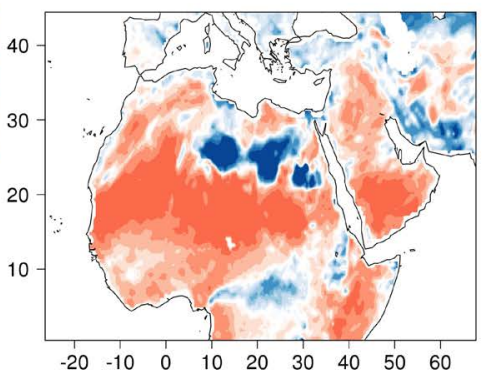

(e) CL-WRF5 vs. OBS. (PR)

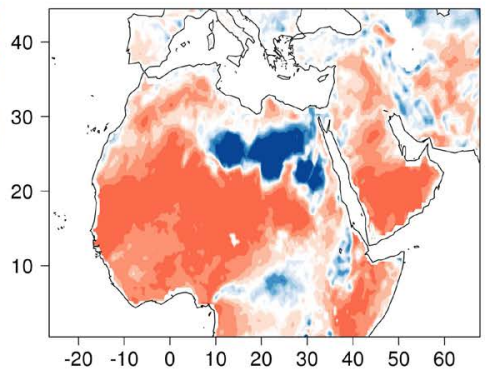

(h) CL-WRF8 vs. OBS. (PR)

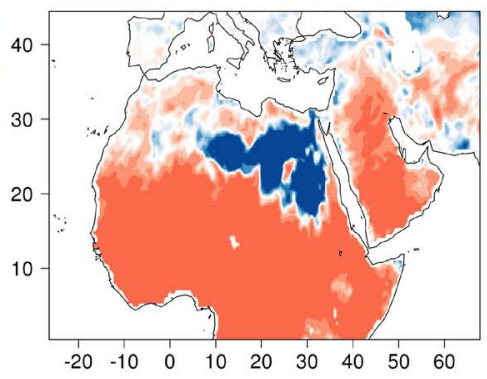

(k) CL-WRF11 vs. OBS. (PR)

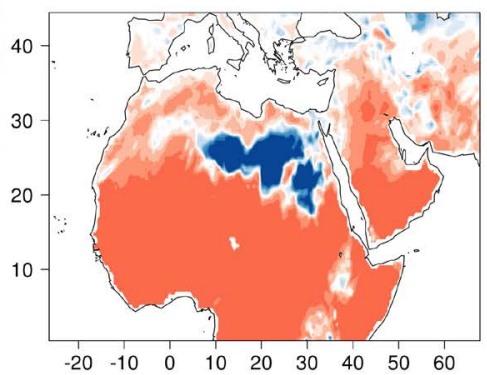

(c) CL-WRF3 vs. OBS. (PR)

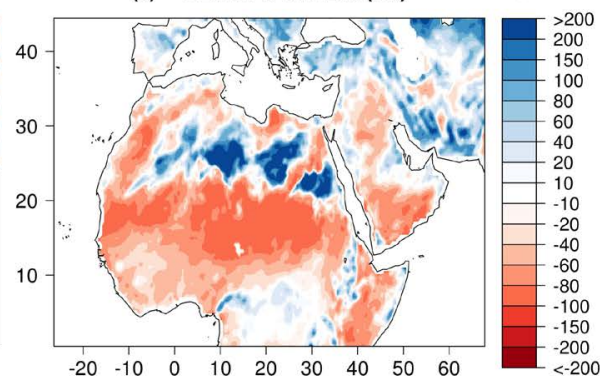

(f) CL-WRF6 vs. OBS. (PR)

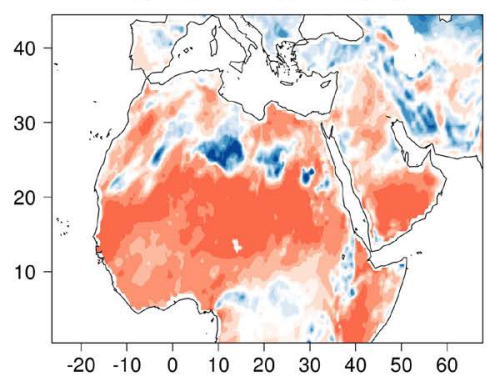

(i) CL-WRF9 vs. OBS. (PR)

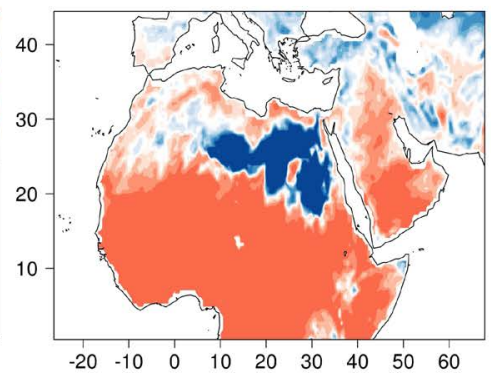

(I) CL-WRF12 vs. OBS. (PR)

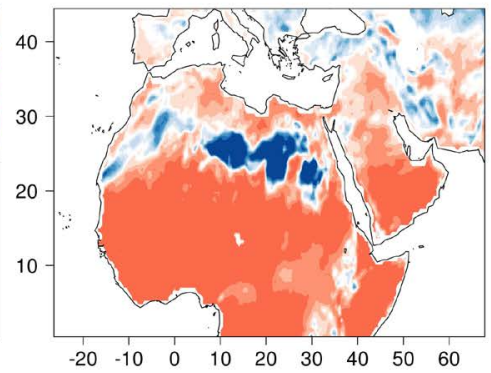

Figure 11. Mean annual precipitation (PR) fractional (\%) biases of the 12 CLWRF simulations relative to the average of the observational datasets (December 1988-November 1990).

est sensitivity to the selection of the CUM parameterization. In general, the KF scheme is relatively wetter comparing to the BMJ and GD schemes (Figure 13-bottom panels). The mean PR difference of the two latter schemes (Figure 13-top right panel) is limited to localized regions in the tropics and is less in terms of PR amounts. The annual mean PR differences between the two tested PBL schemes are of less importance and found only over the tropics. Locally, the YSU scheme appears to be wetter (300 - $900 \mathrm{~mm} /$ year) compared to MYJ (not shown).

\subsection{Selecting the Best-Performing Configuration}

The four statistical metrics described in the methods section were applied to all grid points of the domain. Results averaged over the core-MENA subdomain are presented in Table 3. Regarding TX and TN, the correlation 


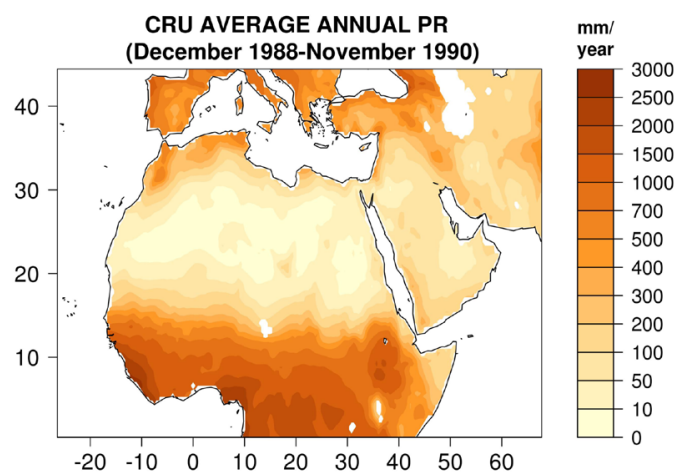

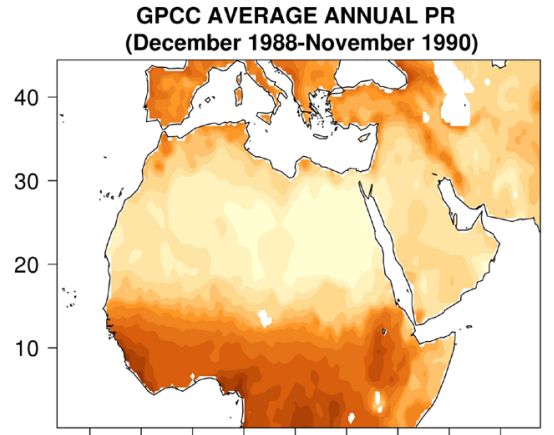

$\begin{array}{lllllllll}-20 & -10 & 0 & 10 & 20 & 30 & 40 & 50 & 60\end{array}$

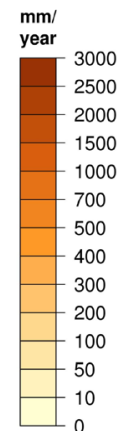

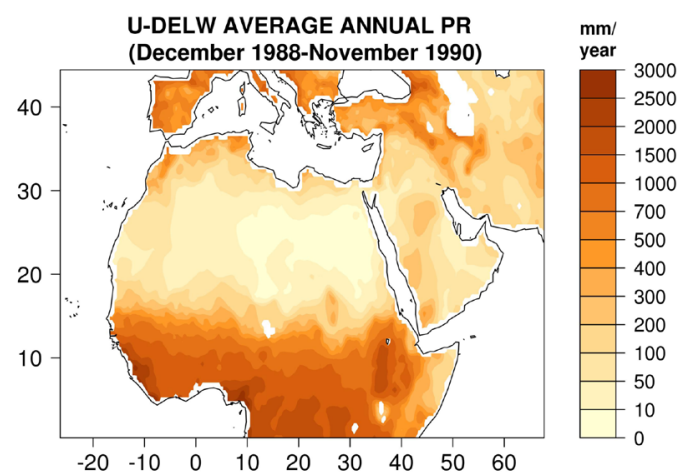

Figure 12. CRU (top left panel), GPCC (top right panel) and University of Delaware (bottom panel) precipitation, averaged for the period December 1988-November 1990.
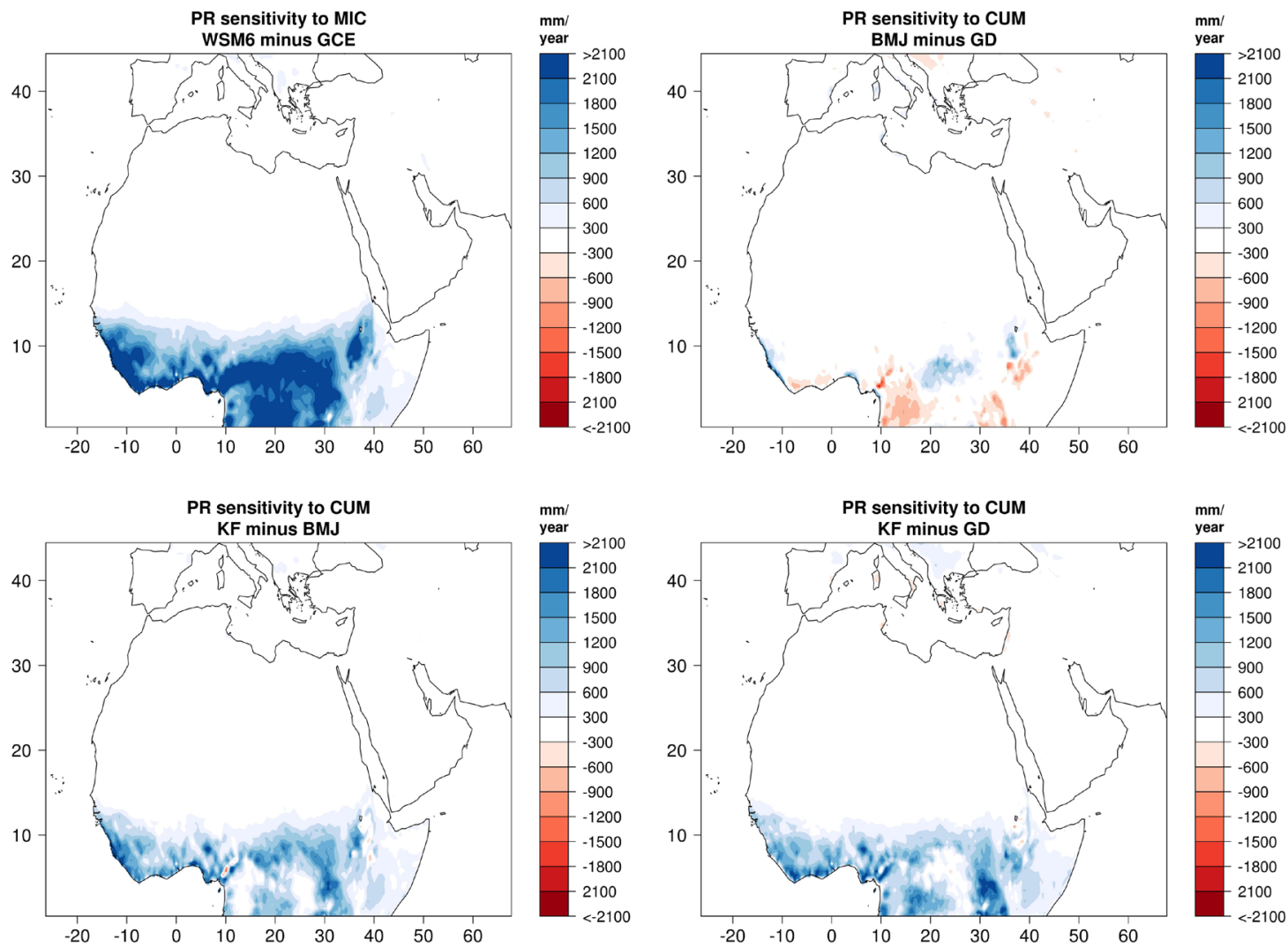

Figure 13. Precipitation (PR) sensitivity to the MIC (top left panel) and CUM (top right and bottom panels) physics selection. 
Table 3. Statistical metrics for maximum (TX), minimum (TN) temperature and precipitation (PR) comparing CRU data with the 12 CLWRF simulations for the core MENA subdomain (MNA) outlined in Figure 3. The best performing simulations for each metric and variable are in bold.

\begin{tabular}{|c|c|c|c|c|c|c|c|c|c|c|c|c|c|}
\hline & Sim. ID: & 1 & 2 & 3 & 4 & 5 & 6 & 7 & 8 & 9 & 10 & 11 & 12 \\
\hline \multirow{4}{*}{ TX } & COR & 0.95 & 0.95 & 0.94 & 0.95 & 0.94 & 0.94 & 0.83 & 0.83 & 0.83 & 0.91 & 0.89 & 0.90 \\
\hline & MAE & 1.82 & 1.95 & 1.91 & 1.95 & 2.25 & 2.11 & 4.70 & 5.54 & 5.03 & 2.79 & 3.58 & 2.95 \\
\hline & MIA & 0.80 & 0.80 & 0.79 & 0.79 & 0.77 & 0.77 & 0.66 & 0.62 & 0.65 & 0.75 & 0.71 & 0.73 \\
\hline & STDE & 0.14 & 0.25 & 0.02 & 0.22 & 0.79 & 0.29 & 1.57 & 1.71 & 1.78 & 1.26 & 1.82 & 1.34 \\
\hline \multirow{4}{*}{ TN } & COR & 0.94 & 0.94 & 0.94 & 0.94 & 0.95 & 0.95 & 0.76 & 0.77 & 0.78 & 0.92 & 0.91 & 0.93 \\
\hline & MAE & 2.60 & 2.86 & 2.62 & 3.46 & 3.84 & 3.53 & 5.54 & 6.11 & 5.71 & 4.61 & 5.36 & 4.64 \\
\hline & MIA & 0.73 & 0.71 & 0.73 & 0.66 & 0.64 & 0.66 & 0.53 & 0.50 & 0.52 & 0.58 & 0.54 & 0.58 \\
\hline & STDE & 0.44 & 0.31 & 0.29 & 0.36 & 0.08 & 0.25 & 0.26 & 0.30 & 0.17 & 0.25 & 0.12 & 0.06 \\
\hline \multirow{4}{*}{ PR } & COR & 0.37 & 0.41 & 0.38 & 0.37 & 0.38 & 0.41 & 0.23 & 0.21 & 0.23 & 0.27 & 0.25 & 0.29 \\
\hline & MAE & 12.54 & 11.80 & 11.89 & 11.31 & 12.56 & 12.05 & 15.12 & 15.14 & 14.95 & 13.95 & 14.32 & 13.94 \\
\hline & MIA & 0.48 & 0.42 & 0.44 & 0.43 & 0.39 & 0.40 & 0.30 & 0.28 & 0.31 & 0.31 & 0.27 & 0.31 \\
\hline & STDE & 0.88 & 5.57 & 7.69 & 4.74 & 9.18 & 9.67 & 14.28 & 14.98 & 14.33 & 13.93 & 15.65 & 13.96 \\
\hline
\end{tabular}

and index of agreement scores are clearly higher for the WSM6 microphysics cluster of simulations (IDs 1, 2, 3, $4,5,6)$. This is also evident from the time-series of Figure 7. Similarly, for these runs, the mean absolute biases and the difference in standard deviation are lower. For the calculations of the PR statistics the monthly averages of the three available datasets where used. Independent dataset statistical analysis was also performed, but since the values where very similar only the ones for the averaged OBS are presented in Table 3. As expected, PR scores are generally lower than the ones for temperature and there is no apparent advantage between any of the 12 simulations. However, slightly better statistics are found for the WSM6-driven runs. Moreover, as seen in Figure 14, enhanced precipitation months are simulated reasonably well in runs with the WSM6 scheme (green and blue lines). In contrast, GCE driven simulations miss the rainy season in the core MENA region (red and grey lines). These relatively wetter periods in this subdomain mainly occur during summer, related to the WestAfrican monsoon.

To objectively select the best performing simulation we have ranked their skill and counted the number of grid points where each of the 12 runs performed best. We consider the simulation with the higher number of ranking-first grid points as the best performer. These results are presented in percentages in the three panels of Figure 15. There is a clear distinction between the runs under the WSM6 microphysics scheme over the simulations using GCE, with the former performing generally better. This is in agreement with the discussion of the biases presented in the previous sections. The simulation with run ID \#1 appears to be the one that ranks first in most of the MENA-CORDEX domain. This percentage is almost 40\% when considering every land grid point of the domain (Figure 15-left panel), while this number is reduced to around 22\% for grid points over the sub-regions of special interest (Figure 12-middle panel). The selected physics for this run were the YSU planetary boundary layer, the KF cumulus and WSM6 microphysics schemes. The second best-performing simulation is the one with ID \#3. This run was ranked first in about $10 \%$ of the total and around $15 \%$ of the sub-region grid points. The configuration differs from the ID \#1 only in the CUM parameterization where the BM scheme is used instead of KF.

\subsection{Station Comparison}

Similarly to the analysis presented in the previous paragraph, a comparison between simulations and ECA\&D stations was performed. More information regarding the location of the 12 stations and their data availability over the simulation period is presented in Figure 3 (right panel) and Table 2. The closest model land grid point to the station coordinates is considered to be the most representative. The mean monthly distribution of TX for the two years of simulations is illustrated in Figure 16. In addition to the ECA\&D station data, TX of the closest 


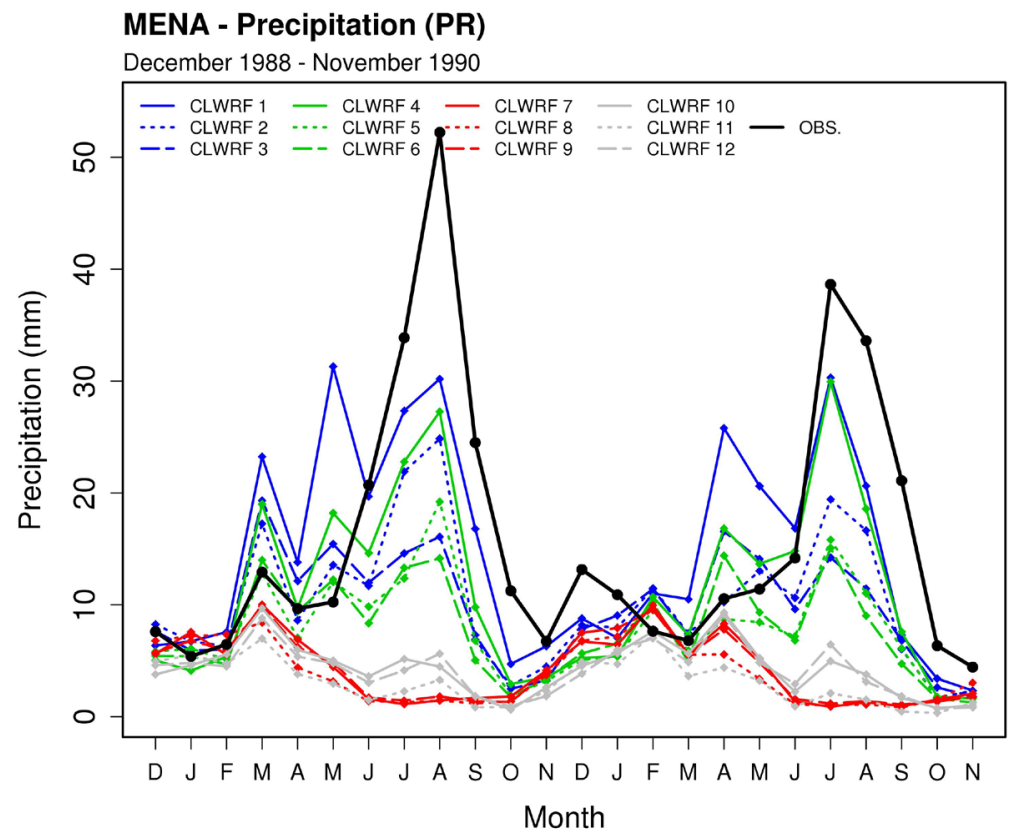

Figure 14. Monthly precipitation time-series of the observational data and 12 CLWRF simulations averaged for the core MENA subdomain defined in Figure 3.
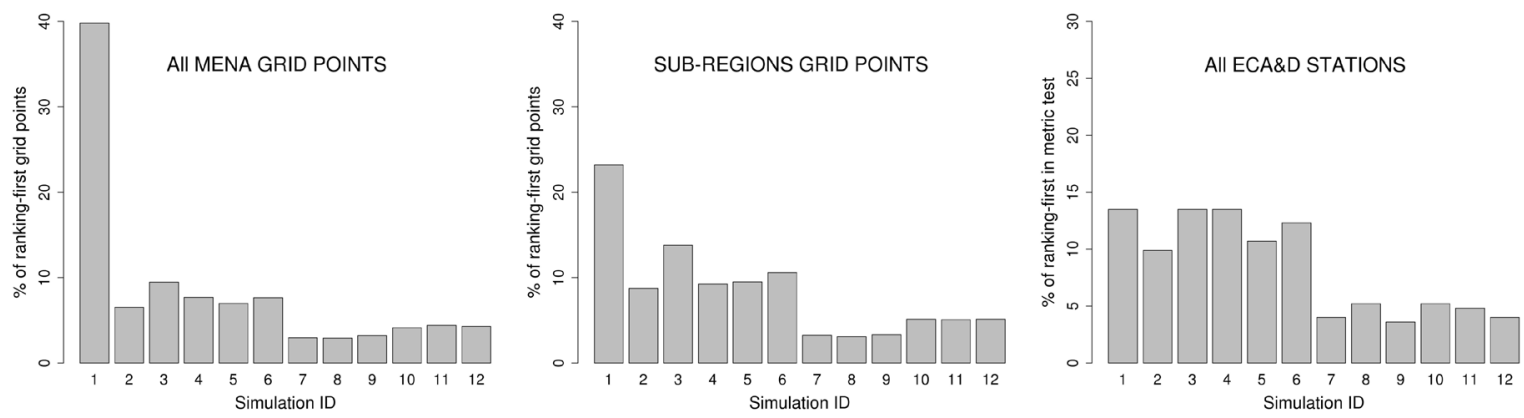

Figure 15. Percentages of ranking-first grid points for the 12 CLWRF simulations and for all grid points (left), for grid points over the sub-regions defined in Figure 3 averaged (middle) and for all statistical metrics tests for 12 ECA \& D stations (right).

CRU grid point is also presented for comparison. Overall there is a good representation of TX for most of the simulations. A TX underestimation over some stations can be explained by the relatively unrealistic surface topography resolved in this model resolution $(\approx 50 \mathrm{~km})$. For example, for the Algeria, Palmyra, Kerman, Eilat and Van stations the model elevation is much higher than in reality (Table 2). A vertical lapse rate temperature correction could improve the statistics by a more realistic TX representation over these stations. Besides the resolution-related elevation errors the station location and the nearest grid points in the model may lead to discrepancies. Nevertheless, here we perform a comparison between model configurations, and the absolute (dis) agreement is not our foremost objective. In agreement with the gridded data comparison, the simulations that are driven by the WSM6 microphysics scheme (IDs 1, 2, 3, 4, 5 and 6) are consistently closer to the ECA \& D station data. As expected, remarkable differences are found even between the station and gridded observational data as a result of the relatively coarse resolution of the latter and the interpolation methods applied for their construction. For most of the cases though, the modeled TX is closer to the gridded CRU data, which are of similar horizontal resolution.

The seasonal cycle of TN is generally captured well by the model and for most of the ECA \& D stations (Figure 17). Exception is the Gabes station where the peak TN occurs 3 months earlier than observations. A general underestimation of $\mathrm{TN}$, more pronounced during the summer season, is evident in most stations. In agreement 

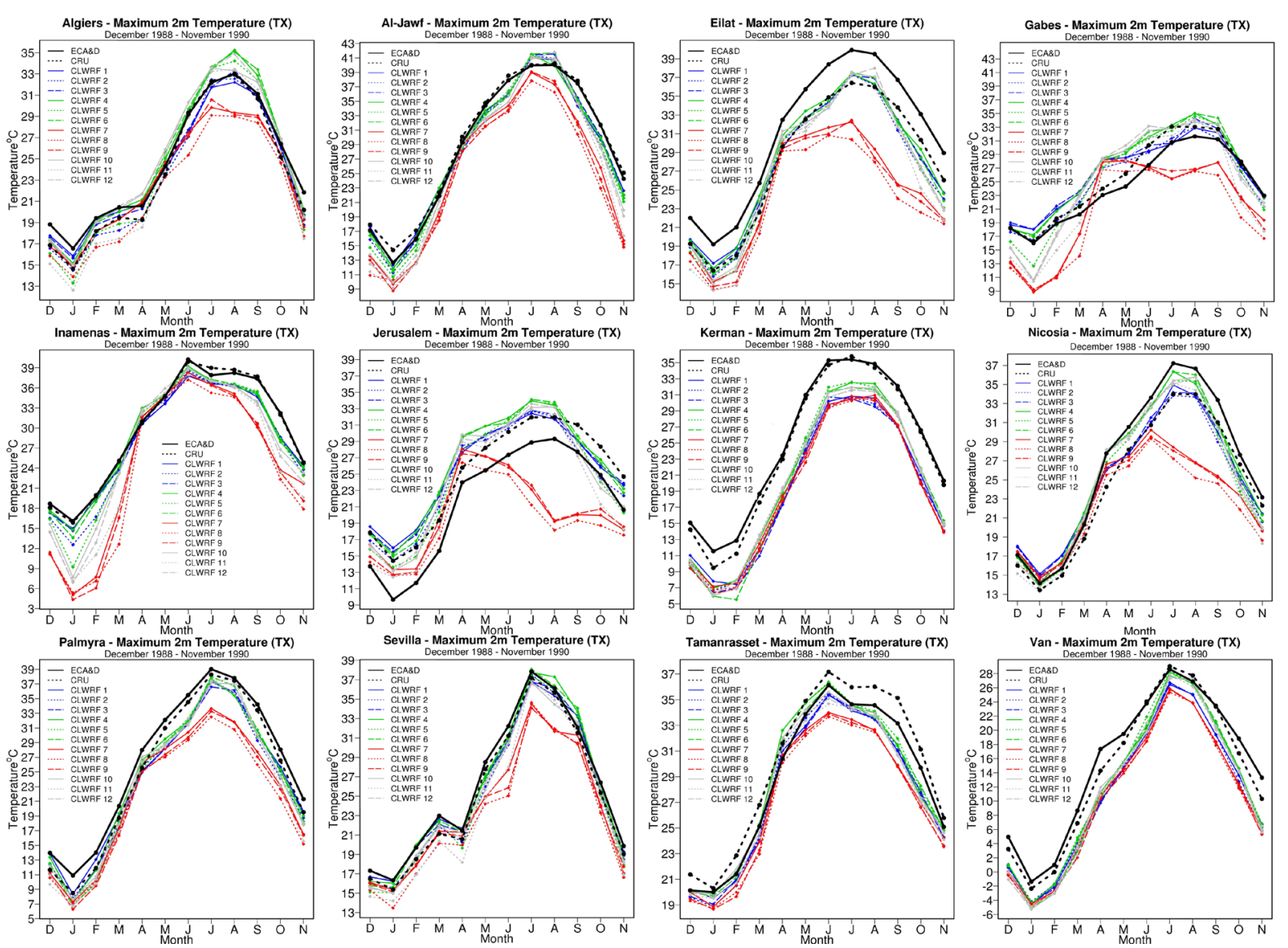

Figure 16. Mean monthly maximum temperature (TX) climatology for 12 ECA \& D stations and the closest grid point of the 12 CLWRF simulations and CRU data for the period December 1988-November 1990.

with TX, the WSM6-driven simulations (blue and green lines) are in most of the cases performing better.

Time-consistent PR data for the period of comparison were more difficult to be obtained. Unfortunately, only at nine of the twelve stations PR was recorded adequately (or data were available). The comparison between these stations and the 12 different physics setups of CLWRF are presented in Figure 18. The monthly average of the three observational datasets (OBS) is additionally presented in Figure 18. As expected, and in agreement with the relevant bias maps and the calculated statistical metrics, the model skill to reproduce PR is worse compared to temperature. In some cases, such as Gabes, Van, Kerman and Algiers stations, the annual cycle of PR is realistically reproduced, however the amounts of PR are overestimated. In all aforementioned stations the model elevation is higher than in reality and this can induce relatively larger water amounts related to orographic precipitation triggering. From Figure 18 it is not evident which physics configuration represents PR most realistically.

The ranking procedure discussed in the previous paragraph was also applied for the 12 ECA \& D stations. The statistical metrics between the 12 simulations and one relatively well performing (Seville) and one poor-performing model location (Jerusalem) are indicatively presented in Table 4 and Table 5. For all stations, the number of metrics where the simulation ranks first was recorded and the results are presented in percentages in the right panel of Figure 15. Again, there is a clear advantage of using the WSM6 microphysics scheme (simulation IDs 1, 2, 3, 4, 5, and 6). The aforementioned simulations were ranked equally first in about $13 \%$ - 15\% of the applied ranking tests. This is consistent with the results presented in the previous sections.

\section{Discussion and Conclusions}

Typically, global climate change projections suggest that the region that encompasses the Middle East and North Africa will be relatively strongly affected by climate change. In the framework of obtaining improved regional 

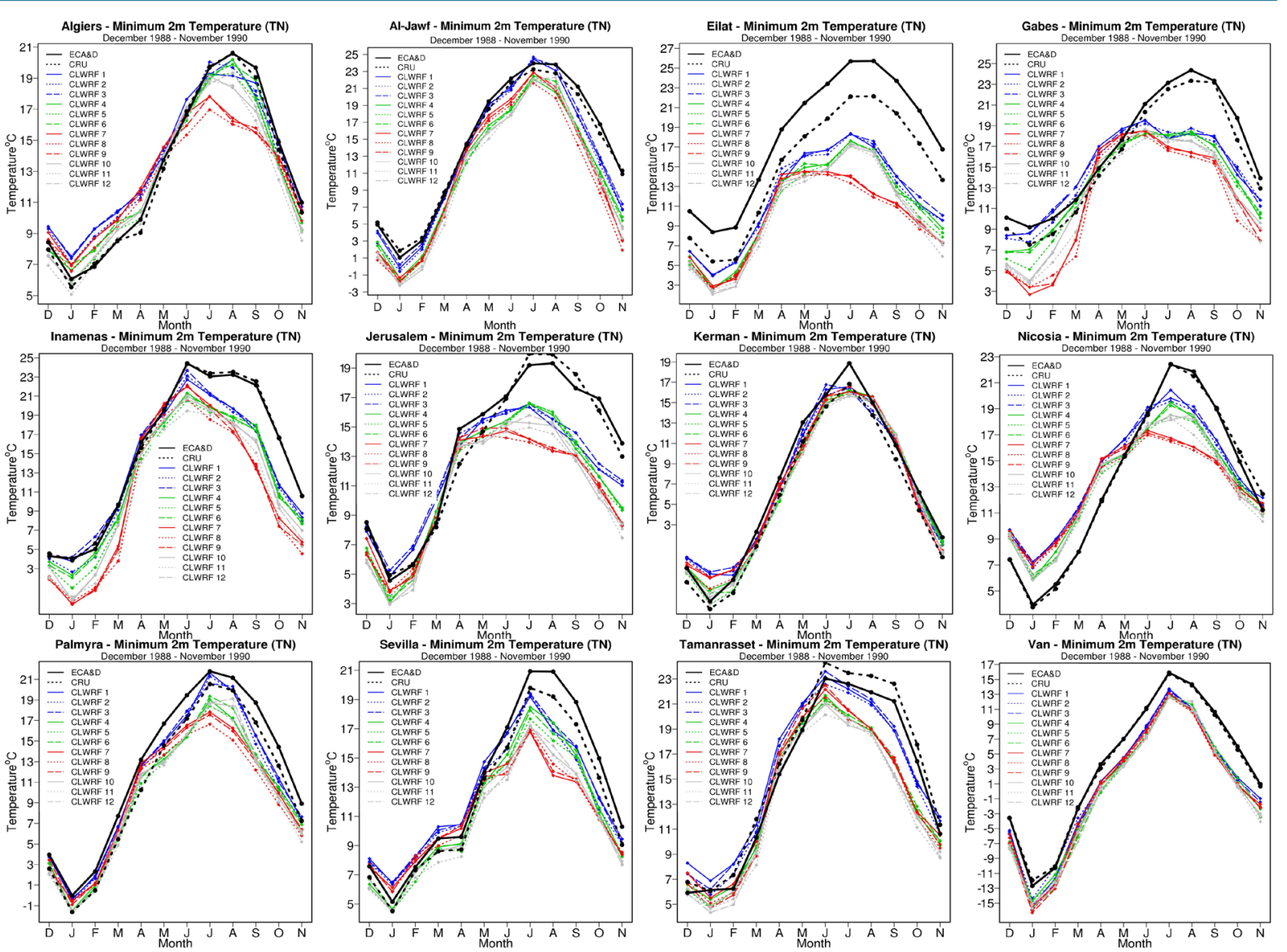

Figure 17. Mean monthly minimum temperature (TN) climatology for 12 ECA \& D stations and the closest grid point of the 12 CLWRF simulations and CRU data for the period December 1988-November 1990.

climate projections, we investigated the effect of several different physical processes parameterizations in the WRF meso-scale model for the MENA domain, focusing on near surface minimum, maximum temperature and precipitation, parameters that are relevant for impact studies. In this study, the sensitivity to microphysics, cumulus (convection) and boundary layer parameterizations was tested using twelve different configurations in two-year simulations.

Our results show that maximum and minimum temperatures are most sensitive to the microphysics parameterization selection. In particular, runs based on the WSM6 scheme are in closer agreement with a gridded observational dataset (CRU) and station data. This is mainly related to the more realistic cloud cover produced by this scheme, while the GCE scheme overestimates cloud cover and consequently strongly underestimates temperature at the surface. The temperature sensitivity to the cumulus parameterization is negligible in part because convection mainly occurs during the evening hours, hence after the time when TX is reached and well before TN temperatures typically occur within the daily cycle. The impact of the PBL scheme is important mostly for $\mathrm{TN}$ and mainly over parts of the domain in desert areas but is of less significance compared to the representation of microphysics.

As may be expected, precipitation is more difficult to model realistically. The scores of the statistical metrics are in general lower than the values for TX and TN scores, nevertheless, for the relatively dry region of interest (core-MENA subdomain) the model and especially WSM6-driven simulations show smaller biases and seem to be able to capture the annual precipitation cycle adequately. PR is found to be sensitive mainly to the selection of cumulus and microphysics parameterizations. In absolute precipitation amounts this is particularly evident in the tropics, although this is a part of the domain less relevant for impact studies over the traditional definition of MENA region. Precipitation in the driest Saharan part of the domain, as indicated by the relative biases, appears to be insensitive to the physics selection and all simulations are found to be relatively wetter than indicated by 

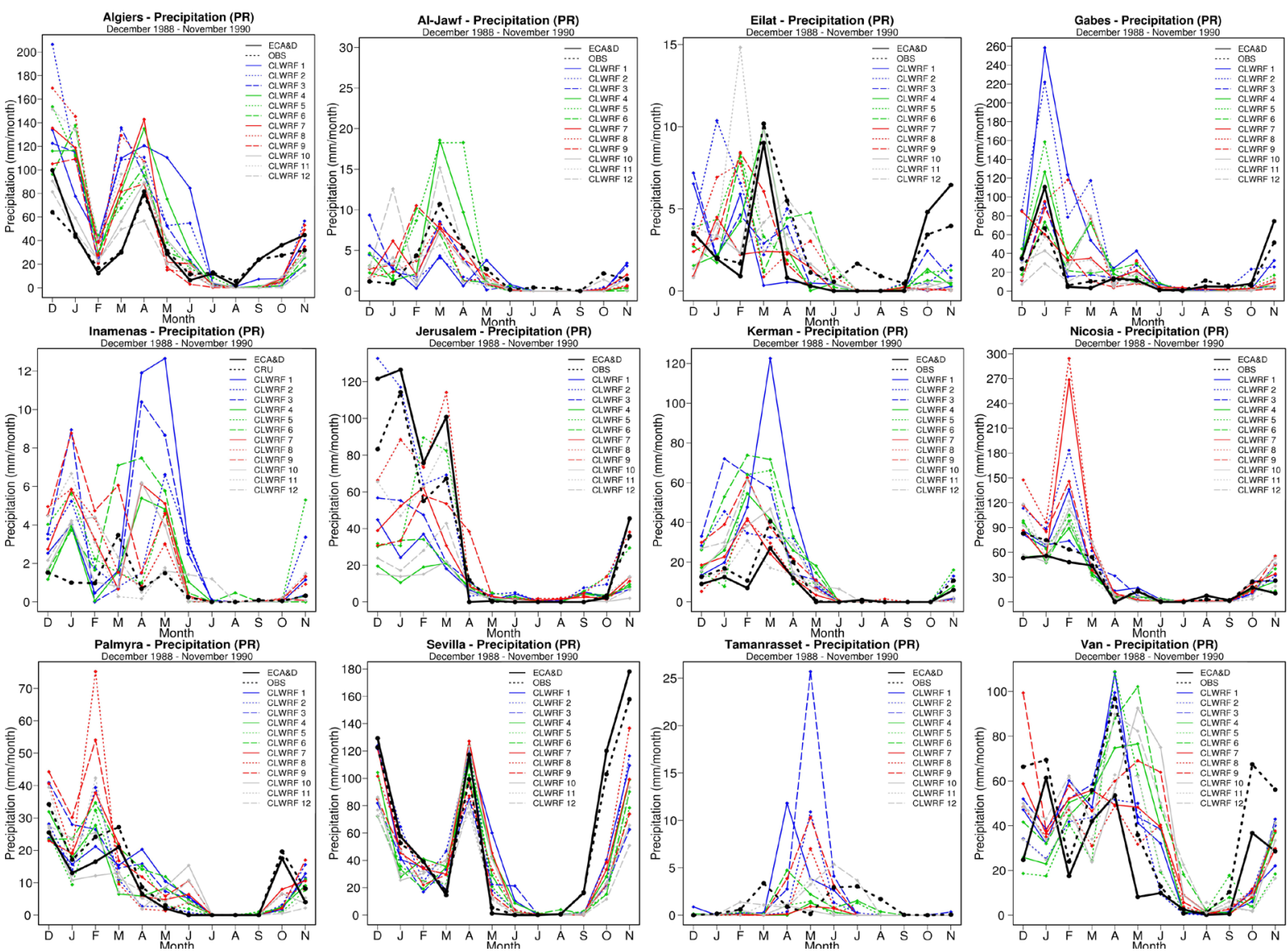

Figure 18. Mean monthly precipitation (TN) climatology for 12 ECA \& D stations and the closest grid point of the 12 CLWRF simulations and CRU data for the period December 1988-November 1990.

Table 4. Same as Table 3 for the Seville station.

\begin{tabular}{|c|c|c|c|c|c|c|c|c|c|c|c|c|c|}
\hline & Sim. ID: & 1 & 2 & 3 & 4 & 5 & 6 & 7 & 8 & 9 & 10 & 11 & 12 \\
\hline \multirow{4}{*}{ TX } & COR & 0.99 & 0.99 & 0.99 & 0.99 & 0.99 & 0.99 & 0.97 & 0.97 & 0.96 & 0.99 & 0.98 & 0.99 \\
\hline & MAE & 0.92 & 1.31 & 0.95 & 0.94 & 1.41 & 1.01 & 2.35 & 3.24 & 2.57 & 1.36 & 2.49 & 1.42 \\
\hline & MIA & 0.93 & 0.90 & 0.92 & 0.93 & 0.89 & 0.92 & 0.80 & 0.73 & 0.78 & 0.89 & 0.81 & 0.89 \\
\hline & STDE & 0.12 & 0.27 & 0.00 & 0.40 & 0.68 & 0.51 & 0.69 & 0.45 & 0.92 & 0.14 & 0.62 & 0.28 \\
\hline \multirow{4}{*}{ TN } & COR & 0.96 & 0.96 & 0.97 & 0.98 & 0.98 & 0.98 & 0.92 & 0.95 & 0.93 & 0.97 & 0.97 & 0.98 \\
\hline & MAE & 1.47 & 1.58 & 1.39 & 1.76 & 2.15 & 1.88 & 2.35 & 2.32 & 2.41 & 2.37 & 2.71 & 2.40 \\
\hline & MIA & 0.82 & 0.81 & 0.84 & 0.80 & 0.75 & 0.78 & 0.69 & 0.70 & 0.68 & 0.72 & 0.68 & 0.71 \\
\hline & STDE & 1.28 & 1.35 & 1.21 & 0.94 & 1.13 & 1.06 & 2.05 & 2.03 & 2.10 & 1.44 & 1.45 & 1.45 \\
\hline \multirow{4}{*}{ PR } & COR & 0.87 & 0.87 & 0.83 & 0.87 & 0.84 & 0.85 & 0.84 & 0.87 & 0.86 & 0.77 & 0.87 & 0.81 \\
\hline & MAE & 23.52 & 25.27 & 34.78 & 29.01 & 29.34 & 32.56 & 24.30 & 29.01 & 28.83 & 33.15 & 32.24 & 33.72 \\
\hline & MIA & 0.77 & 0.76 & 0.59 & 0.70 & 0.59 & 0.63 & 0.77 & 0.70 & 0.68 & 0.64 & 0.64 & 0.59 \\
\hline & STDE & 20.57 & 18.21 & 41.95 & 28.18 & 32.84 & 37.87 & 21.00 & 28.18 & 36.81 & 33.99 & 37.65 & 44.99 \\
\hline
\end{tabular}

the CRU data.

In order to objectively select the best-performing physics configuration for the present application of CLWRF, a ranking based on four statistical metrics between the 12 simulations and the observational data was performed. 
Table 5. Same as Table 3 for the Jerusalem station.

\begin{tabular}{cccccccccccccc}
\hline & Sim. ID: & $\mathbf{1}$ & $\mathbf{2}$ & $\mathbf{3}$ & $\mathbf{4}$ & $\mathbf{5}$ & $\mathbf{6}$ & $\mathbf{7}$ & $\mathbf{8}$ & $\mathbf{9}$ & $\mathbf{1 0}$ & $\mathbf{1 1}$ & $\mathbf{1 2}$ \\
\hline \multirow{4}{*}{ TX } & COR & 0.96 & 0.96 & $\mathbf{0 . 9 8}$ & 0.96 & 0.95 & 0.96 & 0.71 & 0.72 & 0.74 & 0.93 & 0.93 & 0.95 \\
& MAE & 4.06 & 3.27 & 3.96 & 4.47 & 3.34 & 4.28 & 4.13 & 4.19 & 3.87 & 3.42 & $\mathbf{2 . 7 9}$ & 3.24 \\
& MIA & 0.63 & 0.71 & 0.64 & 0.61 & 0.73 & 0.64 & 0.60 & 0.60 & 0.64 & 0.72 & $\mathbf{0 . 7 8}$ & 0.73 \\
& STDE & 1.33 & 0.65 & 1.07 & 0.52 & 0.36 & 0.27 & 1.92 & 2.15 & 1.73 & $\mathbf{0 . 1 7}$ & 0.79 & 0.16 \\
& COR & 0.92 & 0.93 & 0.93 & $\mathbf{0 . 9 4}$ & 0.93 & $\mathbf{0 . 9 4}$ & 0.90 & 0.91 & 0.89 & 0.91 & 0.91 & 0.92 \\
TN & MAE & 2.14 & 2.04 & $\mathbf{2 . 0 1}$ & 2.44 & 2.51 & 2.31 & 3.02 & 3.08 & 3.00 & 3.08 & 3.16 & 3.04 \\
& MIA & 0.74 & $\mathbf{0 . 7 5}$ & $\mathbf{0 . 7 5}$ & 0.73 & 0.72 & $\mathbf{0 . 7 5}$ & 0.65 & 0.65 & 0.66 & 0.67 & 0.66 & 0.67 \\
& STDE & 1.34 & 1.36 & 1.44 & 0.71 & 0.83 & $\mathbf{0 . 6 7}$ & 1.38 & 1.44 & 1.18 & 0.78 & 0.99 & 0.68 \\
& COR & 0.78 & 0.73 & 0.62 & 0.66 & 0.55 & 0.59 & $\mathbf{0 . 8 2}$ & 0.66 & 0.54 & 0.76 & 0.77 & 0.54 \\
PR & MAE & 29.93 & 19.07 & 27.11 & 34.16 & 26.38 & 30.06 & 24.96 & 34.16 & 28.82 & 34.33 & 17.97 & 30.14 \\
& MIA & 0.44 & $\mathbf{0 . 7 8}$ & 0.55 & 0.28 & 0.61 & 0.44 & 0.60 & 0.28 & 0.55 & 0.27 & 0.75 & 0.43 \\
& STDE & 40.11 & $\mathbf{1 . 9 3}$ & 33.78 & 49.04 & 25.55 & 42.59 & 35.08 & 49.04 & 30.99 & 50.59 & 25.68 & 41.39 \\
\hline
\end{tabular}

For the largest number of grid points, the simulation with ID \#1 was found to yield the best performance. The configuration for this run includes the YSU planetary boundary layer, the KF cumulus and WSM6 microphysics schemes, in addition to the CAM long and shortwave radiation and the NOAH land surface models that are used in all simulations.

Although the seasonal analysis has not been extensively discussed, the bias patterns are very similar to the annual ones while their values, especially of precipitation, might differ according to the season. More extensive evaluation, including longer-term simulations that will allow the calculation of trends will follow using the configuration with the optimal physics schemes selected here.

An in-depth analysis of physical scheme inter-comparison is not within the scope of the current study although we do recognize the importance of understanding the underlying aspects of the physics. For example, it is intriguing that the two cloud microphysics schemes used here have contrasting performance in the temperature biases although they are both bulk, mixed-phase schemes, including six classes of water substances, and both originate from the parameterization of Lin et al. [47]. Our findings may trigger further studies over this region including several schemes to diagnose in detail the finer, controlling components of the physics (as for example, in Wu and Petty [48]).

The results should be considered representative only for the MENA domain and not necessarily for other regions. For other locations with different prevailing weather patterns, surface topography and meteorological feedbacks, the results might differ. We cannot exclude that configurations that were not tested here might potentially perform better. In addition, parameterizations kept fixed in this study, such as (LSM or RAD) can also affect the results and likely reduce the model biases; any additional consideration of these two processes here would at least quadruple the number of simulations, being prohibitive with respect to the available computational resources. The tested key parameterizations leading to larger differences under present conditions may well be different under future climate change conditions [49]; nevertheless, this study can serve as a reference for potential WRF users in the region.

\section{Acknowledgements}

The research leading to these results has received funding from the European Research Council under the European Union's Seventh Framework Programme (FP7/2007-2013)/ERC grant agreement $n^{\circ} 226144$. This work was supported by the Cy-Tera Project (NEA YПO $\Delta \mathrm{OMH} / \Sigma T P A T H / 0308 / 31$ ), which is co-funded by the European Regional Development Fund and the Republic of Cyprus through the Research Promotion Foundation. We also acknowledge the data providers in the ECA\&D project.

\section{References}

[1] Van Oldenborgh, G.J., Collins, M., Arblaster, J., Christensen, J.H., Marotzke, J., Power, S.B., Rummukainen, M.T. and 
Zhou, T. (2013) Annex I: Atlas of Global and Regional Climate Projections. In: Stocker, T.F., Qin, D., Plattner, G.K., Tignor, M., Allen, S.K., Boschung, J., Nauels, A., Xia, Y., Bex, V. and Midgley, P.M., Eds., Climate Change 2013: The Physical Science Basis, Contribution of Working Group I to the Fifth Assessment Report of the Intergovernmental Panel on Climate Change, Cambridge University Press, Cambridge, and New York.

[2] Lelieveld, J., Hadjinicolaou, P., Kostopoulou, E., Chenoweth, J., Maayar, M., Giannakopoulos, C., Hannides, C., Lange, M.A., Tanarhte, M., Tyrlis, E. and Xoplaki, E. (2012) Climate Change and Impacts in the Eastern Mediterranean and the Middle East. Climatic Change, 114, 667-687. http://dx.doi.org/10.1007/s10584-012-0418-4

[3] Chenoweth, J., Hadjinicolaou, P., Bruggeman, A., Lelieveld, J., Levin, Z., Lange, M.A., Xoplaki, E. and Hadjikakou, M. (2011) Impact of Climate Change on the Water Resources of the Eastern Mediterranean and Middle East Region: Modeled 21st Century Changes and Implications. Water Resources Research, 47, Article ID: W06506+.

[4] Myers, N., Mittermeier, R.A., Mittermeier, C.G., da Fonseca, G.A.B. and Kent, J. (2000) Biodiversity Hotspots for Conservation Priorities. Nature, 403, 853-858. http://dx.doi.org/10.1038/35002501

[5] Fischlin, A., Midgley, G.F., Price, J.T., Leemans, R., Gopal, B., Turley, C., Rounsevell, M.D.A., Dube, O.P., Tarazona, J. and Velichko, A.A. (2007) Ecosystems, Their Properties, Goods and Services. In: Parry, M., Canziani, O.F., Palutikof, J.P., van der Linden, P. and Hanson, C.E., Eds., Climate Change 2007: Impacts, Adaptation and Vulnerability. Contribution of Working Group II to the Fourth Assessment Report of the Intergovernmental Panel on Climate Change, Cambridge University Press, Cambridge.

[6] Leung, L., Ruby, L., Mearns, O., Giorgi, F. and Wilby, R.L. (2003) Regional Climate Research. Bulletin of the American Meteorological Society, 84, 89-95. http://dx.doi.org/10.1175/BAMS-84-1-89

[7] Déqué, M., Jones, R.G., Wild, M., Giorgi, F., Christensen, J.H., Hassell, D.C., Vidale, P.L., Rockel, B., Jacob, D., Kjellström, E., de Castro, M., Kucharski, F. and van den Hurk, B. (2005) Global High Resolution Versus Limited Area Model Climate Change Projections over Europe: Quantifying Confidence Level from PRUDENCE Results. Climate Dynamics, 25, 653-670. http://dx.doi.org/10.1007/s00382-005-0052-1

[8] Skamarock, W.C., et al. (2008) A Description of the Advanced Research WRF Version 3. NCAR Technical Notes, NCAR/TN-4751STR.

[9] Salathé, E.P., Leung, L.R., Qian, Y. and Zhang, Y. (2010) Regional Climate Model Projections for the State of Washington. Climatic Change, 102, 51-75. http://dx.doi.org/10.1007/s10584-010-9849-y

[10] Chotamonsak, C., Salathé, E.P., Kreasuwan, J., Chantara, S. and Siriwitayakorn, K. (2011) Projected Climate Change over Southeast Asia Simulated Using a WRF Regional Climate Model. Atmospheric Science Letters, 12, $213-219$. http://dx.doi.org/10.1002/asl.313

[11] Nikulin, G., Jones, C., Giorgi, F., Asrar, G., Büchner, M., Cerezo-Mota, R., Christensen, O.B., Déqué, M., Fernandez, J., Hänsler, A., van Meijgaard, E., Samuelsson, P., Sylla, M.B. and Sushama, L. (2012) Precipitation Climatology in an Ensemble of CORDEX-Africa Regional Climate Simulations. Journal of Climate, 25, 6057-6078. http://dx.doi.org/10.1175/JCLI-D-11-00375.1

[12] Soares, P., Cardoso, R., Miranda, P., Medeiros, J., Belo-Pereira, M. and Espirito-Santo, F. (2012) WRF High Resolution Dynamical Downscaling of ERA-Interim for Portugal. Climate Dynamics, 39, 2497-2522. http://dx.doi.org/10.1007/s00382-012-1315-2

[13] Warrach-Sagi, K., Schwitalla, T., Wulfmeyer, V. and Bauer, H.S. (2013) Evaluation of a Climate Simulation in Europe Based on the WRF-NOAH Model System: Precipitation in Germany. Climate Dynamics, 41, 755-774. http://dx.doi.org/10.1007/s00382-013-1727-7

[14] Warrach-Sagi, K., Schwitalla, T., Bauer, H.S. and Wulfmeyer, V. (2013) A Regional Climate Model Simulation for EURO-CORDEX with the WRF Model. In: Resch, M., et al. Eds., Sustained Simulation Performance 2013, Springer International Publishing, Berlin.

[15] García-Díez, M., Fernández, J., Fita, L. and Yagüe, C. (2013) Seasonal Dependence of WRF Model Biases and Sensitivity to PBL Schemes over Europe. Quarterly Journal of the Royal Meteorological Society, 139, 501-514. http://dx.doi.org/10.1002/qi.1976

[16] Dudhia, J. (2014) A History of Mesoscale Model Development. Asia-Pacific Journal of Atmospheric Sciences, 50, 121-131. http://dx.doi.org/10.1007/s13143-014-0031-8

[17] Evans, J., Ekström, M. and Ji, F. (2012) Evaluating the Performance of a WRF Physics Ensemble over South-East Australia. Climate Dynamics, 39, 1241-1258. http://dx.doi.org/10.1007/s00382-011-1244-5

[18] Bukovsky, M. and Karoly, D. (2009) Precipitation Simulations Using WRF as a Nested Regional Climate Model. Journal of Applied Meteorology and Climatology, 48, 2152-2159. http://dx.doi.org/10.1175/2009JAMC2186.1

[19] Ruiz, J., Saulo, J.C. and Nogués-Paegle, J. (2010) WRF Model Sensitivity to Choice of Parameterization over South America: Validation against Surface Variables. Monthly Weather Review, 138, 3342-3355. http://dx.doi.org/10.1175/2010MWR3358.1 
[20] Flaounas, E., Bastin, S. and Janicot, S. (2011) Regional Climate Modelling of the 2006 West African Monsoon: Sensitivity to Convection and Planetary Boundary Layer Parameterisation Using WRF. Climate Dynamics, 36, $1083-1105$. http://dx.doi.org/10.1007/s00382-010-0785-3

[21] Crétat, J., Pohl, B., Richard, Y. and Drobinski, P. (2012) Uncertainties in Simulating Regional Climate of Southern Africa: Sensitivity to Physical Parameterizations Using WRF. Climate Dynamics, 38, 613-634. http://dx.doi.org/10.1007/s00382-011-1055-8

[22] Fita, L., Fernández, J. and Gracia-Diez, M. (2010) CLWRF: WRF Modifications for Regional Climate Simulation under Future Scenarios. 11th WRF User's Workshop, NCAR, Boulder.

[23] Simmons, A., Uppala, S., Dee, D. and Kobayashi, S. (2006) ERA-Interim: New ECMWF Reanalysis Products from 1989 Onwards. ECMWF Newsletter, 110, 26-35.

[24] Hong, S.Y., Noh, Y. and Dudhia, J. (2006) A New Vertical Diffusion Package with an Explicit Treatment of Entrainment Processes. Monthly Weather Review, 134, 2318-2341. http://dx.doi.org/10.1175/MWR3199.1

[25] Janjic, Z.I. (1994) The Step-Mountain Eta Coordinate Model: Further Developments of the Convection, Viscous Sublayer, and Turbulence Closure Schemes. Monthly Weather Review, 122, 927-945. http://dx.doi.org/10.1175/1520-0493(1994)122<0927:TSMECM>2.0.CO;2

[26] Kain, J.S. and Fritsch, J.M. (1993) Convective Parameterization for Meso-Scale Models: The Kain-Fritsch Scheme. In: Emanuel, K.A. and Raymond, D.J., Eds., The Representation of Cumulus Convection in Numerical Models, American Meteorological Society, Boston, 1-246.

[27] Kain, J.S. (2004) The Kain-Fritsch Convective Parameterization: An Update. Journal of Applied Meteorology, 43, 170181. http://dx.doi.org/10.1175/1520-0450(2004)043<0170:TKCPAU>2.0.CO;2

[28] Betts, A.K. and Miller, M.J. (1986) A New Convective Adjustment Scheme. Part II: Single Column Tests Using GATE Wave, BOMEX, and Arctic Air-Mass Data Sets. Quarterly Journal of the Royal Meteorological Society, 121, 693-709. http://dx.doi.org/10.1002/qj.49711247308

[29] Janjic, Z.I. (2000) Comments on “Development and Evaluation of a Convection Scheme for Use in Climate Models”. Journal of the Atmospheric Science, 57, 3686. http://dx.doi.org/10.1175/1520-0469(2000)057<3686:CODAEO >2.0.CO;2

[30] Hong, S.Y. and Lim, J.O.J. (2006) The WRF Single-Moment Microphysics Scheme (WSM6). Journal of the Korean Meteorological Society, 42, 129-151.

[31] Tao, W.K., Simpson, J. and McCumber, M. (1989) An Ice-Water Saturation Adjustment. Monthly Weather Review, 117, 231-235. http://dx.doi.org/10.1175/1520-0493(1989)117<0231:AIWSA>2.0.CO;2

[32] Collins, W.D., Rasch, P.J., Boville, B.A., Hack, J.J., McCaa, J.R., Williamson, D.L., Kiehl, J.T. and Briegleb, B. (2004) Description of the NCAR Community Atmosphere Model (CAM3.0). Technical Note TN-464+STR, National Center of Atmospheric Research, Boulder.

[33] Tewari, M.F., Chen, W., Wang, J., Dudhia, M.A., LeMone, K., Mitchell, M.E., Gayno, G., Wegiel, J. and Cuenca, R.H. (2004) Implementation and Verification of the Unified NOAH Land Surface Model in the WRF Model. 20th Conference on Weather Analysis and Forecasting. 16th Conference on Numerical Weather Prediction, Seattle, 11-15.

[34] National Center for Atmospheric Research, NCAR (2014) ARW Version 3 Modeling System’s User's Guide. http://www.mmm.ucar.edu/wrf/users/docs/user_guide_V3/ARWUsersGuideV3.pdf

[35] Mooney, P.A., Mulligan, F.J. and Fealy, R. (2012) Evaluation of the Sensitivity of the Weather Research and Forecasting Model to Parameterization Schemes for Regional Climates of Europe over the Period 1990-95. Journal of Climate, 26, 1002-1017. http://dx.doi.org/10.1175/JCLI-D-11-00676.1

[36] Mercader, J., Codina, B., Sairouni, A. and Cunillera, J. (2010) Results of the Meteorological Model WRF-ARW over Catalonia, Using Different Parameterizations of Convection and Cloud Microphysics. Tethys, 7, 75-86. http://dx.doi.org/10.3369/tethys.2010.7.07

[37] Argüeso, D., Hidalgo-Muñoz, J.M., Gámiz-Fortis, S.R., Esteban-Parra, M.J., Dudhia, J. and Castro-Díez, Y. (2011) Evaluation of WRF Parameterizations for Climate Studies over Southern Spain Using a Multistep Regionalization. Journal of Climate, 24, 5633-5651. http://dx.doi.org/10.1175/JCLI-D-11-00073.1

[38] Harris, I., Jones, P.D., Osborn, T.J. and Lister, D.H. (2013) Updated High-Resolution Grids of Monthly Climatic Observations. International Journal of Climatology, 34, 623-642. http://dx.doi.org/10.1002/joc.3711

[39] Gómez-Navarro, J.J., Montávez, J.P., Jerez, S., Jiménez-Guerrero, P. and Zorita, E. (2012) What Is the Role of the Observational Dataset in the Evaluation and Scoring of Climate Models? Geophysical Research Letters, 39, Article ID: L24701. http://dx.doi.org/10.1029/2012GL054206

[40] Tanarhte, M., Hadjinicolaou, P. and Lelieveld, J. (2012) Intercomparison of Temperature and Precipitation Data Sets Based on Observations in the Mediterranean and the Middle East. Journal of Geophysical Research, 117, Article ID: 
D12102. http://dx.doi.org/10.1029/2011JD017293

[41] Schamm, K., Ziese, M., Becker, A., Finger, P., Meyer-Christoffer, A., Schneider, U., Schröder, M. and Stender, P. (2013) Global Gridded Precipitation over Land: A Description of the New GPCC First Guess Daily Product. Earth System Science Data Discussions, 6, 435-464. http://dx.doi.org/10.5194/essdd-6-435-2013

[42] Klein Tank, A.M.G., et al. (2002) Daily Dataset of 20th-Century Surface Air Temperature and Precipitation Series for the European Climate Assessment. International Journal of Climatology, 22, 1441-1453. http://www.ecad.eu http://dx.doi.org/10.1002/joc.773

[43] Willmott, C.J. (1981) On the Validation of Models. Physical Geography, 2, 184-194.

[44] Willmott, C.J. and Matsuura, K. (2005) Advantages of the Mean Absolute Error (MAE) over the Root Mean Square Error (RMSE) in Assessing Average Model Performance. Climate Research, 30, 79-82. http://dx.doi.org/10.3354/cr030079

[45] Legates, D.R. and McCabe, G.J. (1999) Evaluating the Use of "Goodness-of-Fit” Measures in Hydrologic and Hydroclimatic Model Validation. Water Resources Research, 35, 233-241. http://dx.doi.org/10.1029/1998WR900018

[46] Weiss, M., Hurk, B., Haarsma, R. and Hazeleger, W. (2012) Impact of Vegetation Variability on Potential Predictability and Skill of EC-Earth Simulations. Climate Dynamics, 39, 2733-2746. http://dx.doi.org/10.1007/s00382-012-1572-0

[47] Lin, Y.L., Farley, R.D. and Orville, H.D. (1983) Bulk Parameterization of the Snow Field in a Cloud Model. Journal of Climate and Applied Meteorology, 22, 1065-1092. http://dx.doi.org/10.1175/1520-0450(1983)022<1065:BPOTSF>2.0.CO;2

[48] Wu, L. and Petty, G.W. (2010) Intercomparison of Bulk Microphysics Schemes in Model Simulations of Polar Lows. Monthly Weather Review, 138, 2211-2228. http://dx.doi.org/10.1175/2010MWR3122.1

[49] Jerez, S., Montavez, J., Gomez-Navarro, J., Lorente-Plazas, R., Garcia-Valero, J. and Jimenez-Guerrero, P. (2013) A Multi-Physics Ensemble of Regional Climate Change Projections over the Iberian Peninsula. Climate Dynamics, 41, 1749-1768. http://dx.doi.org/10.1007/s00382-012-1551-5 
Scientific Research Publishing (SCIRP) is one of the largest Open Access journal publishers. It is currently publishing more than 200 open access, online, peer-reviewed journals covering a wide range of academic disciplines. SCIRP serves the worldwide academic communities and contributes to the progress and application of science with its publication.

Other selected journals from SCIRP are listed as below. Submit your manuscript to us via either submit@scirp.org or Online Submission Portal.
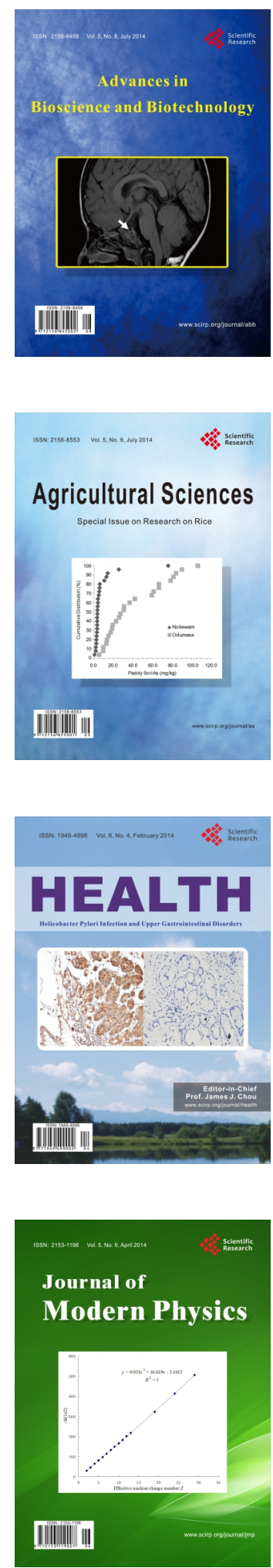
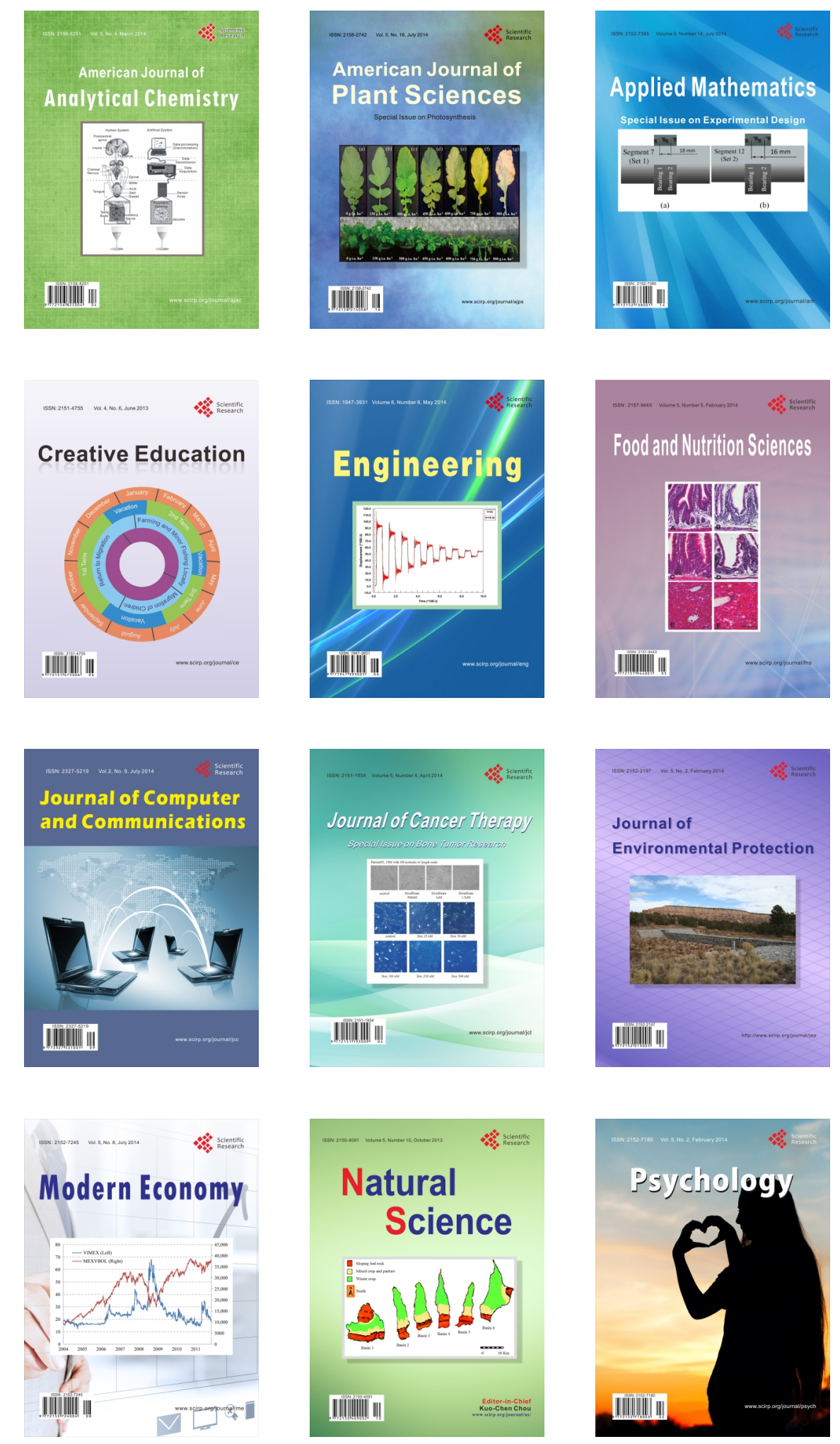